\title{
Uma análise bibliométrica da literatura sobre estratégia e avaliação de desempenho
}

\section{A bibliometric analysis of strategy and performance measurement}

\author{
Rogério Tadeu de Oliveira Lacerda ${ }^{1}$ \\ Leonardo Ensslin ${ }^{1}$ \\ Sandra Rolim Ensslin ${ }^{1}$
}

\begin{abstract}
Resumo: Motivado por uma pesquisa que visa estudar como a avaliação de desempenho pode ser utilizada para apoiar a estratégia empresarial, o presente trabalho visa apresentar um processo para selecionar artigos relevantes sobre o tema, publicados entre os anos 2000 e 2010, a fim de compor o cerne de um referencial bibliográfico sobre o tema em questão. O processo possibilitou identificar 41 artigos relevantes e alinhados com o tema de pesquisa em uma base de dados internacional. Além da seleção de artigos, o presente trabalho realiza uma análise bibliométrica desse portfólio e descreve estatisticamente, para o portfólio selecionado, os artigos mais relevantes, os autores e os periódicos que mais publicaram sobre o tema de avaliação de desempenho em uma perspectiva estratégica. Com os resultados, acadêmicos e praticantes podem desenvolver seus arcabouços teóricos sobre artigos, autores e periódicos que mais se destacam nessa área de pesquisa de avaliação de desempenho e estratégia organizacional.
\end{abstract}

Palavras-chave: Avaliação de desempenho. Estratégia. Decisão. Bibliometria.

\begin{abstract}
Motivated by a study that aims to study how performance measurement can be used to support business strategies, this paper presents a procedure to select relevant articles on the subject in order to compose the core bibliography of this area of knowledge. The process enabled the identification of 41 relevant and aligned articles on the research theme in an international database. In addition to the selection of articles, this paper carries out a bibliometric analysis of this portfolio and describes statistically the most relevant articles, authors, and journals that have published more articles on the topic of performance measurement in a strategic perspective. With the results, academics and practitioners can develop their core collection of articles, authors, and journals that stand out in this research area of performance evaluation and organizational strategy.
\end{abstract}

Keywords: Performance measurement. Strategy. Decision. Bibliometrics.

\section{Introdução}

Por se tratar de um tema multidisciplinar e que remonta há séculos atrás, a definição de estratégia percorre variadas literaturas e essas usam o termo estratégia de formas distintas.

De forma clássica, o termo é associado ao campo militar, como o texto secular de Sun Tzu que data de cerca de 3000 mil anos atrás. A estratégia como instrumento de guerra também se encontra na própria origem da palavra, de raiz grega, significando "arte do general", inspirando impérios a se organizarem de forma a vencer um inimigo ou batalha (MINTZBERG et al., 2003).

Tais vitórias eram perseguidas não somente na competição direta, mas com estratagemas para ludibriar o inimigo e potencializar as forças com as quais irá conseguir seus objetivos, de forma ampla e duradoura.
Os preceitos que originaram a palavra e seu uso preliminar evoluíram ao longo do tempo e foram adaptados aos critérios do momento para que as organizações pudessem se utilizar de tais visões de mundo para avaliar seu sucesso organizacional.

Assim surgem as definições contextualizadas da Administração, que tem sido alvo de pesquisas na comunidade científica e que é o foco da presente pesquisa.

Porém, dado que a estratégia é considerada uma das mais jovens especialidades da Administração, as pesquisas nesse campo têm crescido rapidamente, de forma abrangente e diversa (KETCHEN; BOYD; BERGH, 2008).

Dentro desse contexto diverso, os autores da presente pesquisa entendem que uma gestão bem sucedida é aquela que conquista vantagens

\footnotetext{
${ }^{1}$ Programa de Pós-Graduação em Engenharia de Produção, Universidade Federal de Santa Catarina - UFSC,

Campus Universitário Trindade, CP 476, CEP 88040-900, Florianópolis, SC, Brasil, e-mail: rogerlacerda@gmail.com
}

Recebido em 23/3/2011 — Aceito em 15/6/2011

Suporte financeiro: Nenhum. 
competitivas que gera valor em amplos horizontes de tempo na perspectiva dos gestores, por meio do desenvolvimento, estruturação e reinvenção da utilidade de seus recursos (singularidade), de forma a dificultar a duplicação e/ou imitação por outros atores do ecossistema competitivo (BARNEY; WRIGHT; KETCHEN, 2001).

Essa ótica de entender a gestão estratégica é conhecida como a teoria baseada em recursos (BARNEY, 1991) e, dentre esses recursos, destacam-se as capabilities, que são ativos intangíveis possuídos pela firma, ou com condições potenciais para tal, que são dispostos de uma forma que lhe ofereça vantagens competitivas no mercado (SIMONS; DÁVILA; KAPLAN, 2000; MAKADOK, 2001; HELFAT; PETERAF, 2003).

Em ambientes em rápida evolução, nos quais os gestores, além de dominarem o saber fazer e o intelecto criativo, devem preocupar-se em ter processos ágeis, flexíveis e constantemente inovadores, é que as capabilities melhor evidenciam o seu potencial, pois passam a orquestrar os recursos (e outras capabilities) existentes, tornando-os ativos valiosos, raros, imperfeitamente imitáveis e não substituíveis (BARNEY; WRIGHT; KETCHEN, 2001, WADE; HULLAND, 2004).

Essa capacidade de recombinar recursos de forma evolutiva, fruto do conhecimento propiciado por instrumentos construtivistas, recebe a denominação de dynamic capabilities - DCs (TEECE, 2007) e vem suprir algumas limitações notadas pela comunidade científica à teoria baseada em recursos (MORGAN; VORHIES; MASON, 2009).

Com essa característica de alterar o modus operandi de uma organização, pela maneira pela qual o gestor avalia, organiza e desenvolve seus recursos, Teece (2007) afirma que as dynamic capabilities são, na verdade, meta-competência, que transcendem a competência operacional e se destina a analisar as fontes e métodos das organizações em criação de valor operando em ambientes dinâmicos e de rápidas mudanças.

A ligação entre gestão estratégica e DCs pode ser exemplificada pelo contraponto que Zahra, Sapienza e Davidsson (2006) fazem entre as capabilities operacionais, que resolvem problemas, e as DCs que alteram o modo com que os gestores resolvem seus problemas, ou seja, promovem alguma mudança estrutural (WINTER, 2003; ZOLLO; WINTER, 2002).

Tendo essas definições em conta, as DCs aspiram a ser um framework para explicar uma controversa questão de como um empreendimento e sua equipe de gestão podem (TEECE, 2007):

i. Construir conhecimento sobre o que é importante e como mensurá-lo;

ii. Monitorar, fixar e disseminar conhecimento;

iii. Vislumbrar oportunidades e ameaças potenciais; iv. Tomar decisões coerentes e transparentes, além de aproveitar as oportunidades que surgem em ambientes dinâmicos;

v. Manter-se competitivo continuamente, aperfeiçoando seu desempenho e assim renovando as premissas de ações passadas, e gerando riquezas recorrentes.

Dessa forma, as dynamic capabilities são alcançadas via processos para construir novo conhecimento segundo a perspectiva dos gestores e específicos ao contexto. Conhecimentos existentes a priori podem até mesmo ser uma desvantagem se os gerentes generalizarem demasiadamente as situações passadas (EISENHARDT; MARTIN, 2000).

Esta atividade de construção de conhecimento é conhecida como processo de apoio à decisão construtivista (BANA e COSTA; ENSSLIN, 1999; ENSSLIN et al., 2010b, LACERDA; ENSSLIN; ENSSLIN, 2011a,b; ENSSLIN et al., 2000, DE MORAES et al., 2010). O conhecimento necessita estar comprovadamente resultando em melhorias e para isto necessita ser mensurado. As dynamic capabilities estão desta forma associadas a sistemas de Avaliação de Desempenho, que permitem evidenciar oportunidades e a mensuração de suas contribuições.

Se valendo dos conceitos apregoados, a presente pesquisa expande a abrangência da $\mathrm{AD}$ na gestão estratégica das organizações ao levar em conta o seguinte conceito sobre Avaliação de Desempenho:

Avaliação de Desempenho é o processo para construir conhecimento no decisor, a respeito do contexto específico que se propõe avaliar, a partir da percepção do próprio decisor por meio de atividades que identificam, organizam, mensuram ordinalmente e cardinalmente, e sua integração e os meios para visualizar o impacto das ações e seu gerenciamento. (ENSSLIN, 2010).

Tendo esse conceito como afiliação teórica deste trabalho, a $\mathrm{AD}$ pode então ser utilizada para auxiliar aos gestores no desenvolvimento, estruturação e reinvenção da utilidade de seus recursos (singularidade), de forma a dificultar a duplicação e/ou imitação por outros atores do ecossistema competitivo, consonantes com os modelos teóricos de Porter (1980) e Barney (1991) sobre gestão estratégica.

Como passo fundamental para esse problema de pesquisa, o presente artigo visa:

i. Propor um processo para selecionar referências bibliográficas sobre a avaliação de desempenho em uma perspectiva estratégica; e

ii. Realizar análises bibliométricas sobre os artigos e suas referências, autores e periódicos proeminentes nesse tema.

Para atingir esses objetivos, este estudo adotou o processo denominado ProKnow-C 
(Knowledge Development Process - Constructivist) (ENSSLIN et al., 2010a), que se inicia pelo interesse do pesquisador sobre um determinado tema, bem como suas delimitações e restrições intrínsecas ao contexto acadêmico, em busca da construção do conhecimento no pesquisador, a fim de que ele possa iniciar uma pesquisa científica com fundamentação.

A construção desse conhecimento no pesquisador é aqui representada pela seleção dos artigos relevantes que comporão o portfólio bibliográfico relacionado ao tema de avaliação de desempenho na gestão estratégica, bem como a análise bibliométrica desses artigos.

O conceito de análise bibliométrica se baseia na evidenciação quantitativa dos parâmetros de um conjunto definido de artigos (portfólio bibliográfico) para a gestão da informação e do conhecimento científico de um dado assunto. Os parâmetros observáveis são: os artigos selecionados, suas referências, autores, número de citações e periódicos mais relevantes (ENSSLIN et al., 2010a).

Assim, este artigo se apresenta em cinco seções, além desta introdução. Na seção seguinte se encontra o enquadramento metodológico da presente pesquisa. $\mathrm{Na}$ terceira seção, está o processo de pesquisa em banco de dados e bibliometria. A quarta seção apresenta os procedimentos realizados para atingir o objetivo de pesquisa e seus resultados. Por fim, o artigo se encerra com a seção das referências bibliográficas utilizadas ao longo do texto.

\section{Metodologia}

Esta seção visa enquadrar o presente trabalho científico de forma a dar-lhe sustentação metodológica e possibilitar aos leitores uma contextualização de sob qual ótica a pesquisa foi delineada e executada para atingir seus objetivos e resultados finais.

A opção por um determinado processo metodológico em pesquisa científica está relacionada ao problema a ser pesquisado (MORGAN; SMIRCICH, 1980, TRIVIÑOS, 1987). Sobre esse alinhamento da metodologia com o problema pesquisado, Triviños (1987) denomina como indisciplina o fato de um pesquisador usar um método de pesquisa que não seja coerente com o objeto de estudo, tendendo a misturar autores, citações, metodologias de correntes de pensamento desalinhados, não atentando para as bases do conhecimento científico e o problema a que se propõe resolver.

Em atenção às assertivas acima colocadas, a Figura 1 tem o objetivo de explicitar o enquadramento metodológico que esta pesquisa adotou durante sua execução, explicitando assim os pressupostos que foram utilizados desde seu planejamento até a obtenção dos resultados finais.

\section{Processo de pesquisa em banco de dados e bibliometria}

$\mathrm{O}$ processo de pesquisa científica se inicia com um problema, pergunta ou dúvida, que motiva os pesquisadores a procurarem informações sobre um dado tema em bibliotecas e bases bibliográficas digitais (TASCA et al., 2010).

Com a evolução dos sistemas de informações, evidenciou-se o uso de base de dados, que são sistemas de indexação de periódicos, livros, teses, relatórios, anais de eventos dentre outros, a fim de facilitar as buscas de referências bibliográficas e assim, servirem de plataforma teórica para pesquisas futuras.

Além de ser um instrumento que facilita a recuperação e utilização do conhecimento científico em pesquisas, as bases de dados também contribuem com o estabelecimento de indicadores para visualizar potencial de impacto de um determinado periódico em uma área de conhecimento (PODSAKOFF et al., 2005).

Uma vez determinada a área de conhecimento que será foco da pesquisa, evidencia-se a escolha das palavras-chave que serão utilizadas na busca de referências.

Para mensurar, interpretar e avaliar os resultados obtidos das buscas, pesquisadores recorrem a técnicas bibliométricas, que são análises quantitativas com fins a mensurar a produção e disseminação científica (ARAÚJO, 2006).

\section{Procedimentos para seleção de referencial teórico}

A identificação do estágio atual do conhecimento sobre uma determinada área científica, seja ele teórico ou empírico, é tido como um aspecto crítico para que um pesquisador consiga posicionar seu objetivo de pesquisa em um campo abrangente e disperso como a gestão estratégica (TRANFIELD; DENYER; SMART, 2003).

Com vistas a atender a essa demanda, faz-se necessária uma revisão da literatura acadêmica sobre a área de interesse. Para Karlsson (2008), essas atividades de análise da literatura auxiliam o pesquisador a:

i. Obter o respaldo científico sobre seu trabalho, ao se basear no que tem sido publicado no assunto de interesse;

ii. Justificar a escolha do tema e a contribuição da sua proposta de pesquisa;

iii. Gerar uma justificativa sobre o seu enquadramento metodológico;

iv. Restringir o escopo da pesquisa, tornando-a um projeto factível; 


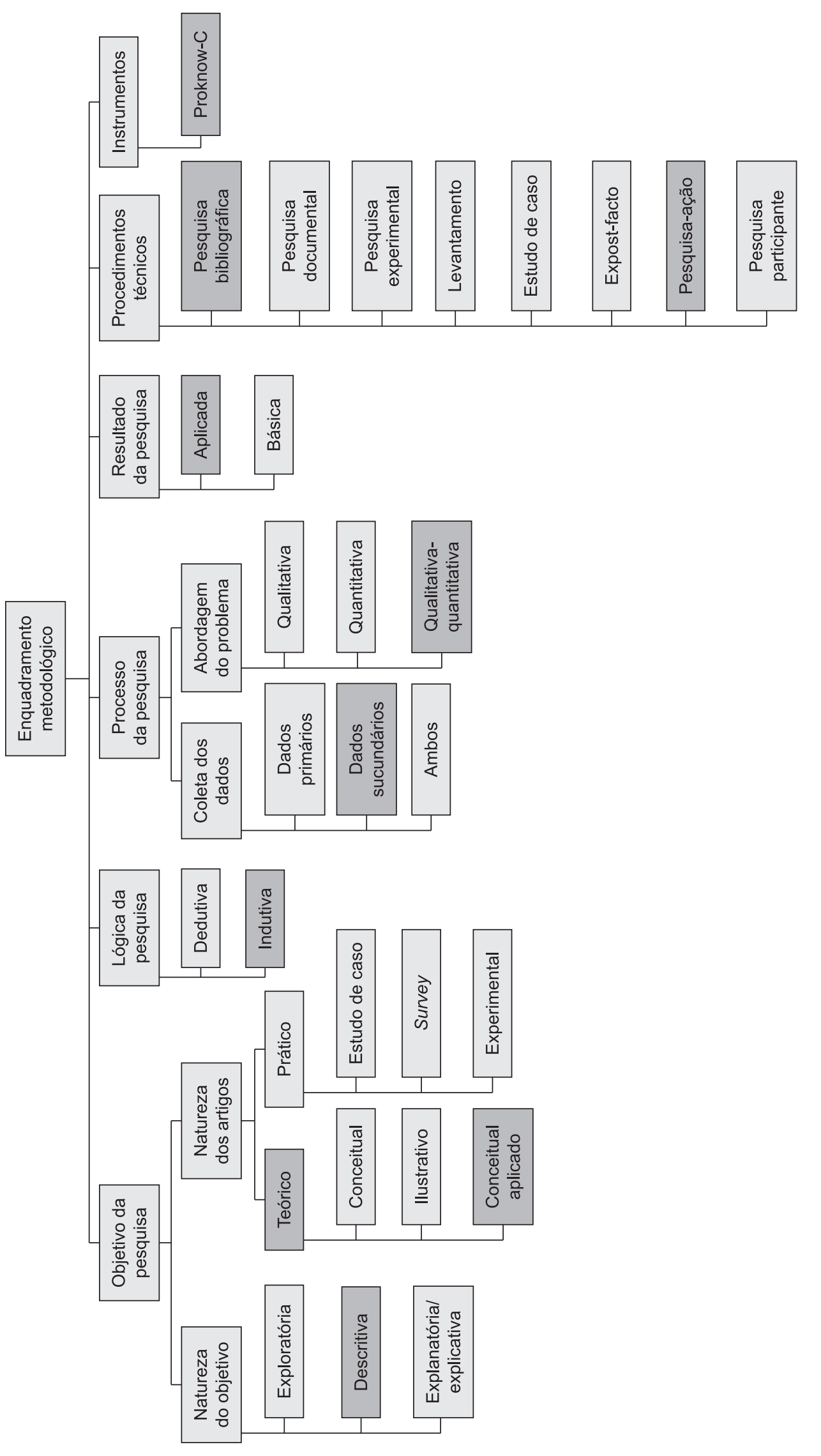

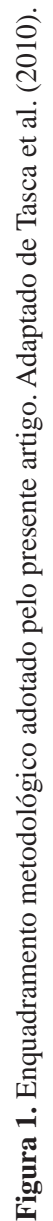


v. Desenvolver no pesquisador habilidades em análise crítica da literatura e no tratamento de informações abrangentes e dispersas.

Com essa relevância, essa seção visa explicitar que procedimentos essa pesquisa utilizou para a seleção de artigos para a elaboração do referencial teórico e construir uma análise bibliométrica do portfólio de artigos selecionados para compor o cerne dessa revisão teórica.

Tais procedimentos para a revisão teórica podem ser divididos em três etapas, detalhadas nas próximas subseções:

i. investigação preliminar;

ii. Seleção dos artigos que comporão o portfólio para a pesquisa;

iii. Análise bibliométrica do portfólio de artigos para o referencial teórico em questão.

\subsection{Investigação preliminar}

\subsubsection{Sobre a cronologia da pesquisa}

Os procedimentos descritos abaixo foram realizados no mês de março de 2010.

\subsubsection{Sobre a base de dados}

A elaboração da revisão teórica sobre o tema de avaliação de desempenho na perspectiva estratégica organizacional iniciou com a escolha da base de dados que delimitará o campo amostral, que resulta em um conjunto de artigos disponíveis a serem considerados no processo de seleção de artigos (TASCA et al., 2010).

Para a presente pesquisa, foi adotada como fonte de dados a base Web of Science (ou ISI), sendo essa a base que dá origem ao JCR (Journal Citation Report), ou seja, ao fator de impacto dos periódicos.

Dessa forma, os autores da pesquisa entendem que essa base constitui-se na de maior contribuição científica atualmente, para o tema pesquisado.

\subsubsection{Sobre as palavras-chave}

Uma vez definido o campo amostral, partiu-se para a escolha das palavras-chave que caracterizar-se-ão pelo primeiro filtro para a seleção dos artigos.
Com vistas a uma pesquisa cuja linha seja de avaliação de desempenho, os pesquisadores determinaram a priori as palavras-chave "performance measurement", "performance evaluation", "performance appraisal", "performance assessment" e "performance management" como termos de um eixo do referencial teórico.

A fim de conjugar as palavras-chave ligadas à avaliação de desempenho com o outro eixo da pesquisa, buscou-se na base ISI, textos publicados depois do ano de 2000, utilizando-se os termos "strategy", "strategic management" e "strategic planning".

Depois de uma leitura não estruturada de títulos e resumos dos artigos mais citados e relacionados com as palavras-chave, notou-se que o termo "strategic management" era o termo mais alinhado com o foco da pesquisa em desenvolvimento.

Porém, a associação das palavras "strategic management" em conjugação com as palavras-chave a priori definidas pelos autores para o eixo de avaliação de desempenho, restringiria inicialmente a massa inicial para um número inferior a 200 artigos.

Com o intuito de iniciar o escrutínio dos artigos a partir de uma amostragem mais representativa, foi definido um conjunto união das sete formas de pesquisa para compor a massa inicial de artigos para início das atividades de seleção de artigos para compor o referencial teórico, conforme observado na Tabela 1.

\subsection{Seleção dos artigos que comporão o portfólio para a pesquisa}

De posse das palavras-chave e da base que se caracteriza pelo campo amostral, pode-se iniciar o processo de seleção dos artigos que comporão o portfólio para a construção do referencial teórico da pesquisa em pauta. Tais atividades foram realizadas entre os dias 13 de março de 2010 a 31 de março de 2010.

Utilizando as palavras-chave anteriormente definidas (Tabela 1) e a data de publicação após o ano de 2000, a busca na base de dados ISI retornou uma massa de 2.345 referências conforme ilustrado na Figura 2.

Para um efetivo gerenciamento dessas referências, elas foram importadas para o aplicativo Endnote (THE THOMSON..., 2008). Com o auxílio dessa ferramenta,

Tabela 1. Definição das palavras-chave de pesquisa.

P1: Topic=("performance measurement") AND Topic=(strategy)
P2: Topic=("performance evaluation") AND Topic=(strategy)
P3: Topic=("performance appraisal") AND Topic=(strategy)
P4: Topic=("performance assessment") AND Topic=(strategy)
P5: Topic=("performance management") AND Topic=(strategy)
P6: Topic=("strategy management")
P7: Topic=("strategic management")

Observação: o termo "TOPIC” acima, indica uma busca no título, palavras-chave e resumo dos artigos. 


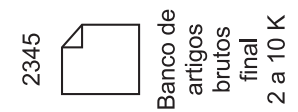

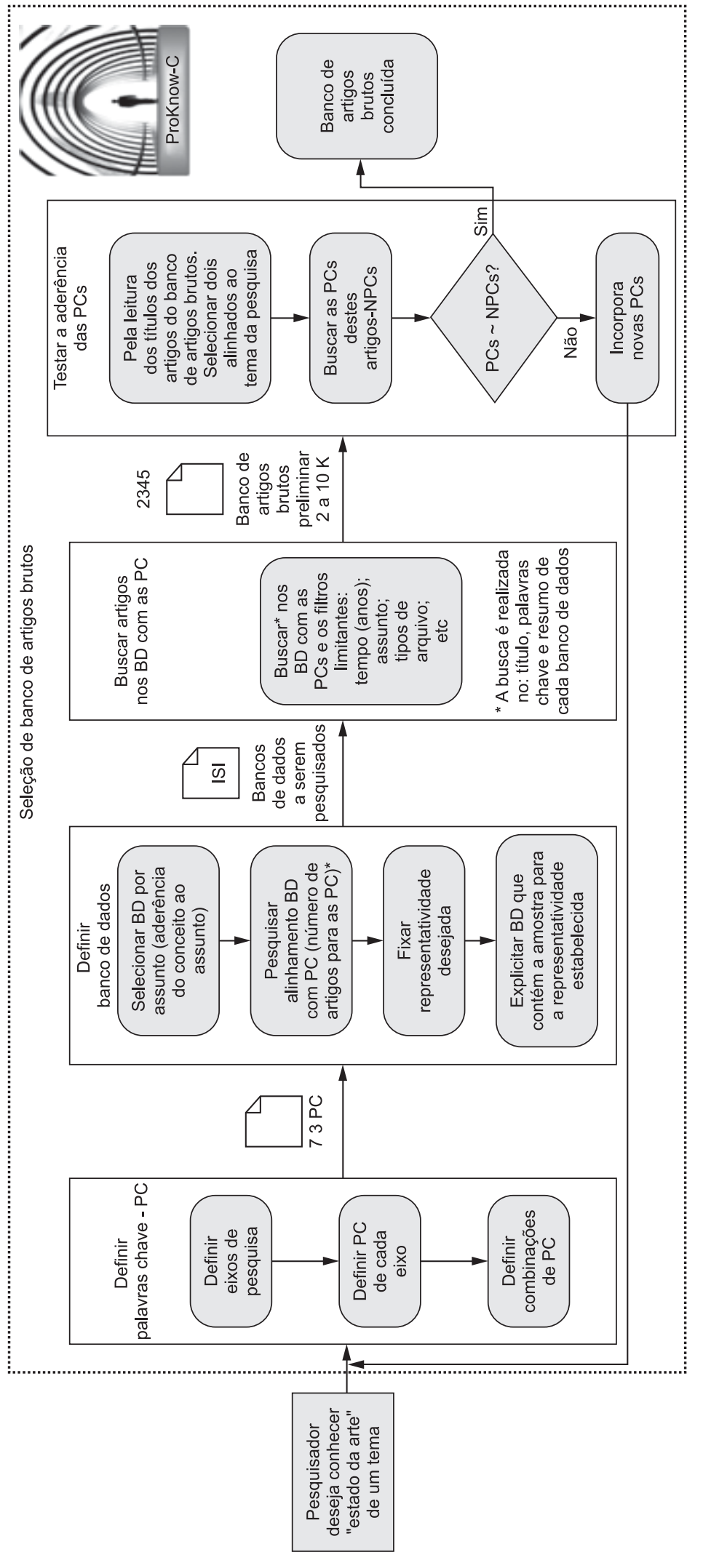

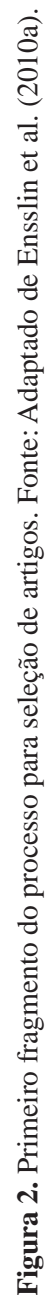


pôde-se identificar 42 referências a serem excluídas da amostra, a citar: 28 referências duplicadas, 4 livros, 1 editorial, 7 book reviews e 2 reedições de artigos anteriores ao ano 2000.

Uma vez realizadas essas 42 exclusões, a biblioteca de artigos se compõe de 2.303 referências, até esse ponto do processo de seleção.

Com as 2.303 referências, passou-se à leitura dos títulos dos artigos para observar o alinhamento desses com a presente pesquisa. Depois dessa análise, 1.972 referências foram excluídas por não terem alinhamento com a pesquisa.

Restando, dessa forma, 331 referências a serem analisadas (Figura 3).

As 331 referências que, pelos seus títulos, se alinhavam com o tema de pesquisa, foram analisadas pelo seu reconhecimento científico desde sua publicação.

Para realizar essa análise, todas as referências foram consultadas pela ferramenta Google Scholar (2010) quanto ao número de citações e ordenadas de forma decrescente.

De posse dessas informações, os autores da presente pesquisa estabeleceram um valor de corte para os artigos mais citados.

Essa delimitação foi definida pelos autores a partir da generalização que Juran (1997) fez para o postulado de Pareto (1896), na qual uma pequena minoria da população representa a maior parte do efeito. Contextualizando tal teorema a essa pesquisa, significa que, se a pesquisa selecionar a minoria dos artigos mais citados, esses representam a maioria do reconhecimento científico presente no conjunto atual de artigos.

Assim, o valor de corte representa a seleção das referências mais citadas até que suas citações representem um valor superior a $85 \%$ de todas as citações obtidas pelos 331 artigos até agora analisados.

Somando todas as citações dos 331 artigos analisados, obtêm-se o número de 9409 citações. Assim, os artigos que individualmente foram citados 26 vezes ou mais, representam 8020 citações, ou seja, $85,24 \%$ de todas as citações das 331 referências até agora selecionadas. Dessa forma, o ponto de corte para aprovar artigos no que se refere ao reconhecimento científico, foi identificado como 26 citações ou mais.

Com essa identificação do valor de corte, 83 artigos foram selecionados pelo número de citações, conforme se pode observar na Figura 4.

Vale ressaltar que os 248 artigos menos citados ainda passarão por um processo de análise sob outros critérios, pelos quais poderão ainda fazer parte do portfólio final de artigos que constituirão parte do referencial teórico da pesquisa.

Uma vez selecionados os artigos com maior reconhecimento científico, foram analisados quanto ao alinhamento do seu resumo (abstract) ao foco da pesquisa em questão.

Dos 83 resumos analisados, 40 foram excluídos devido à falta de alinhamento com o objeto de pesquisa e 10 foram excluídos por não serem disponibilizados no portal da CAPES.

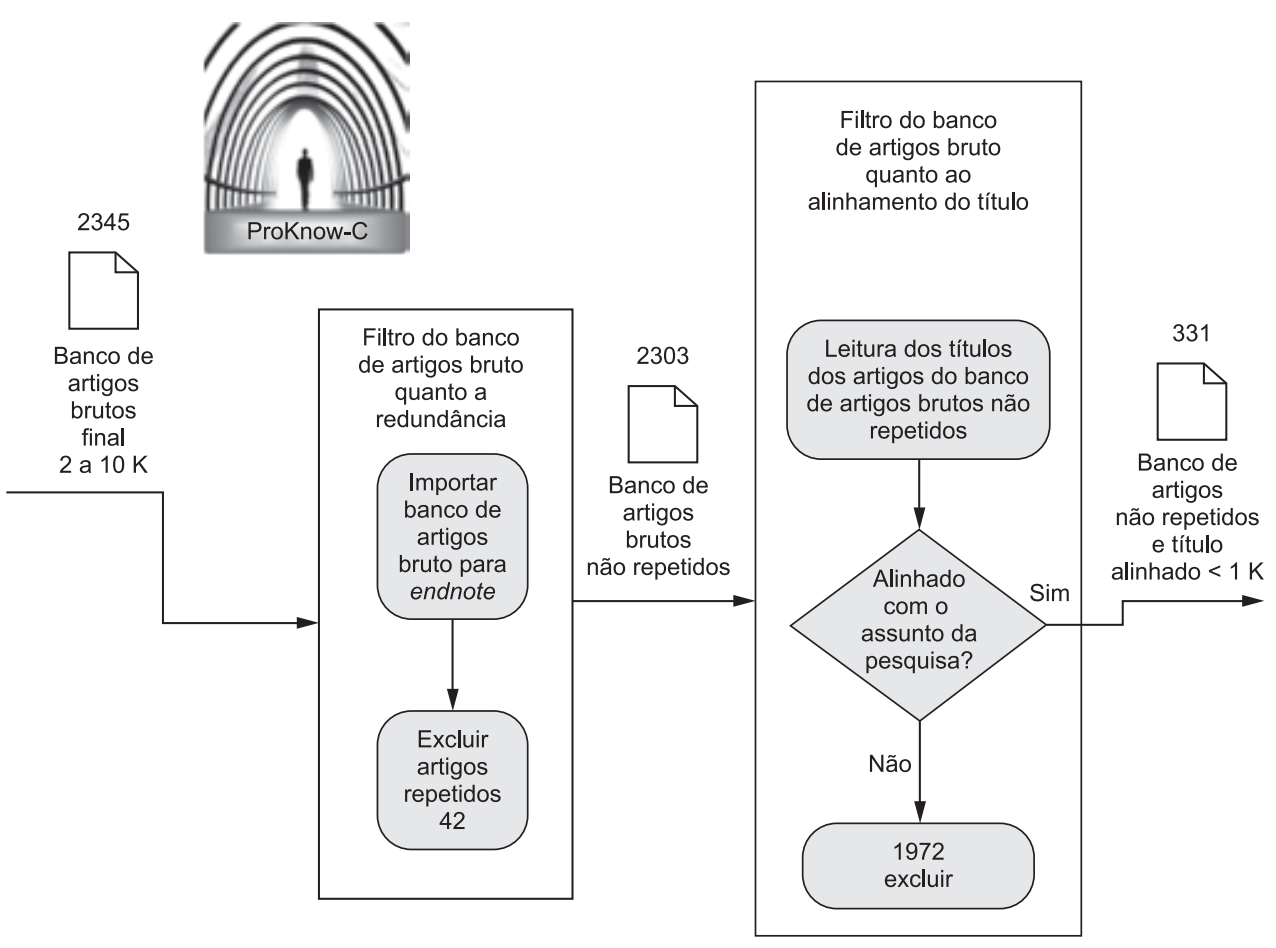

Figura 3. Segundo fragmento do processo para seleção de artigos. Fonte: Adaptado de Ensslin et al. (2010a). 


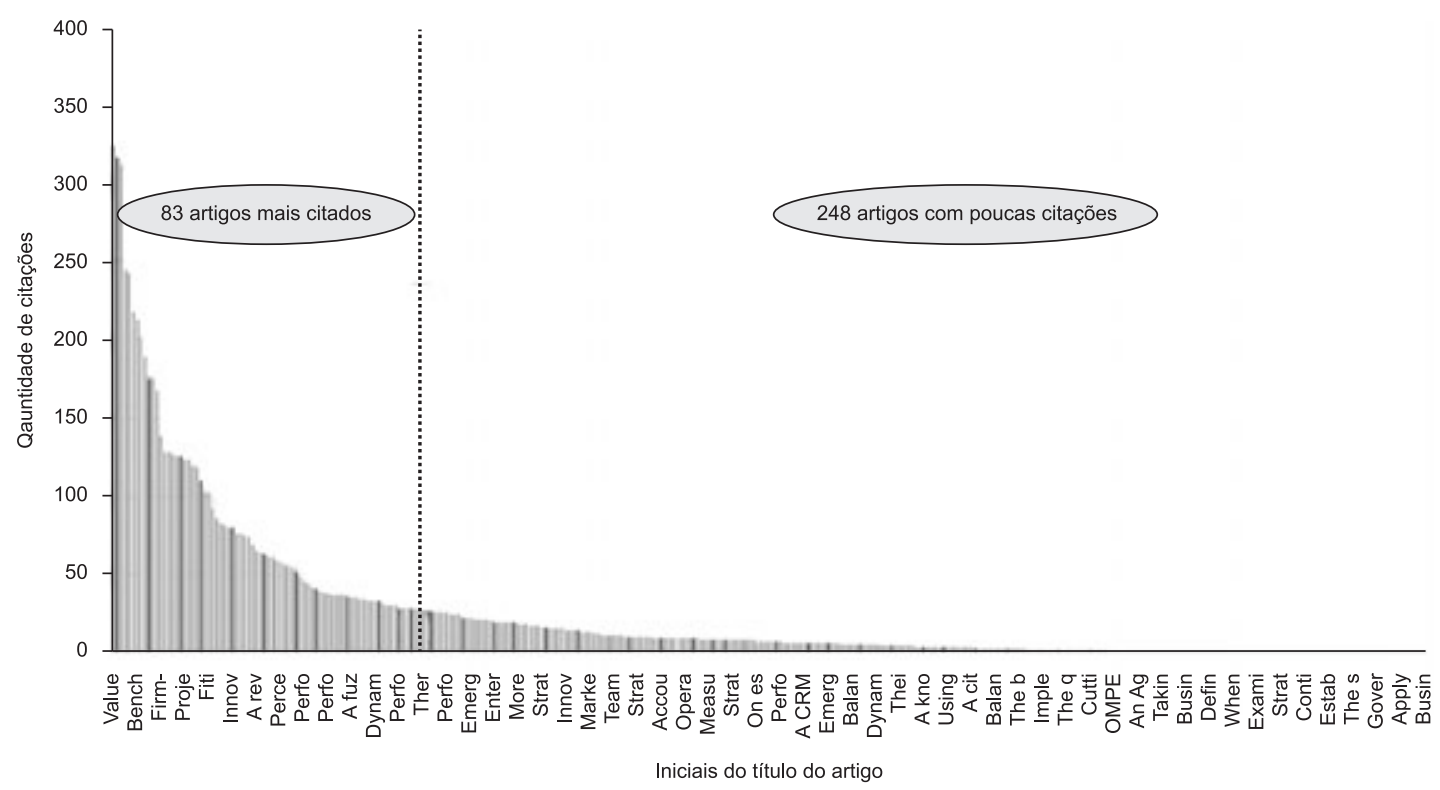

Figura 4. Evidenciação do valor de corte conforme suas citações. Fonte: Autores.

Dessa forma, conforme explicitados na Figura 5, restaram 33 artigos que:

i. Estão alinhados frente à leitura de título e resumo;

ii. Têm um volume de citações relevante;

iii. Têm abstract acessível.

Esses 33 artigos com reconhecimento científico e alinhados com o tema de pesquisa foram selecionados para compor o cerne do referencial teórico sobre avaliação de desempenho em uma perspectiva estratégica.

Porém, mais uma análise é requerida nesses 33 artigos selecionados para que, com mais informação dessa amostra, possa-se avaliar os 248 artigos menos citados e que poderão ainda fazer parte do portfólio final de artigos.

Para que algum artigo com menos citações seja selecionado no portfólio final da pesquisa, o processo definiu duas condições possíveis:

i. Artigos publicados há menos de 2 anos da análise, dado que não tiveram possibilidades de serem bem citados ainda;

ii. Quando artigos publicados há mais de 2 anos, esses devem ser de autoria de algum pesquisador já presente no grupo dos 33 artigos alinhados quanto ao resumo e com relevância científica.

Com essas duas assertivas definidas, dos 248 artigos analisados na repescagem, 100 artigos foram publicados em 2010, 2009 ou 2008.

Dos 148 artigos que foram publicados anteriormente ao ano de 2008, apenas quatro artigos são de autores presentes no portfólio dos artigos já selecionados.

Assim, dos 104 artigos selecionados para o processo de reanálise, 22 artigos foram selecionados após leitura de seus resumos, dado que o alinhamento quanto ao objeto de pesquisa é fundamental para compor o portfólio final de artigos.

A Figura 5 ilustra o processo de reanálise e explicita a quantidade de artigos que passaram em cada atividade do processo de seleção de artigos.

Com esses procedimentos de reanálise dos artigos menos citados, foram selecionados 22 artigos que foram somados aos 33 artigos anteriormente selecionados, perfazendo dessa forma 55 artigos para o portfólio final.

$\mathrm{Na}$ releitura dos resumos desses 55 artigos, todos se apresentaram aderentes quanto ao alinhamento com a pesquisa em pauta.

Como procedimento final, passou-se então à leitura integral deles, a fim de avaliar sua aderência ao tema de pesquisa.

Dessa forma, dos 55 artigos previamente selecionados, 9 trabalhos foram excluídos por não serem disponibilizados de forma integral no portal da CAPES e 5 foram excluídos por desalinhamento ao tema de pesquisa.

A Figura 6 explicita graficamente os procedimentos e os quantitativos das atividades finais para a composição do portfólio final com 41 artigos, nomeados por ordem alfabética do primeiro autor no Quadro 1.

\subsection{Análise bibliométrica do portfólio de artigos para o referencial teórico em questão}

A análise bibliométrica do portfólio de artigos selecionados para o desenvolvimento do referencial 

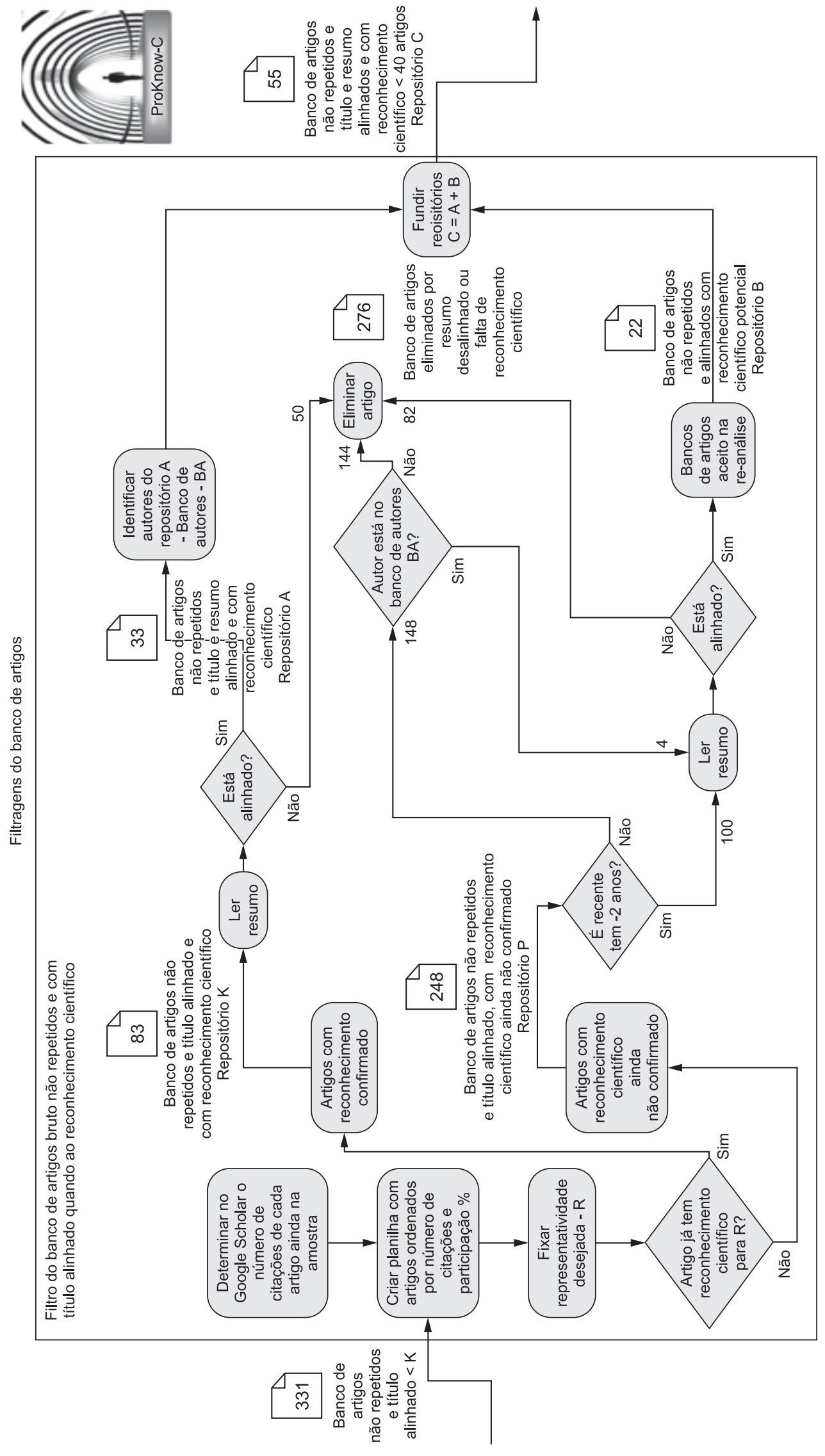

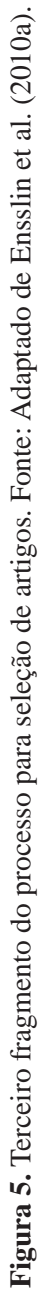


Quadro 1. Artigos que formam o portfólio de artigos para compor o referencial teórico sobre avaliação de desempenho em uma perspectiva estratégica.

AHN, H. Applying the Balanced Scorecard concept: An experience reportn. Long Range Planning, v. 34, n. 4, p. 441-461, 2001. http://dx.doi.org/10.1016/S0024-6301(01)00057-7

BANKER, R. D. et al. The balanced scorecard: Judgmental effects of performance measures linked to strategy. Accounting Review, v. 79, n. 1, p. 1-23, 2004.

BHAGWAT, R.; SHARMA, M. K. Performance measurement of supply chain management: A balanced scorecard approach. Computers \& Industrial Engineering, v. 53, n. 1, p. 43-62, 2007. http://dx.doi.org/10.1016/j. cie.2007.04.001

BITITCI, U. S. et al. Strategy management through quantitative modelling of performance measurement systems. International Journal of Production Economics, v. 69, n. 1, p. 15-22, 2001. http://dx.doi.org/10.1016/S09255273(99)00113-9

BOURNE, M. et al. Designing, implementing and updating performance measurement systems. International Journal of Operations \& Production Management, v. 20, n. 7, p. 754-771, 2000. http://dx.doi. org/10.1108/01443570010330739

CHAN, F. T. S.; QI, H. J.. An innovative performance measurement method for supply chain management. Supply Chain Management-an International Journal, v. 8, n. 3-4, p. 209-223, 2003. http://dx.doi. org/10.1108/13598540310484618

CHEN, C. C. An objective-oriented and product-line-based manufacturing performance measurement. International Journal of Production Economics, v. 112, n. 1, p.380-390, 2008.

DE LIMA, E. P. et al. Taking operations strategy into practice: Developing a process for defining priorities and performance measures. International Journal of Production Economics, v. 122, n. 1, p. 403-418, 2009. http://dx.doi.org/10.1016/j.ijpe.2009.06.022

DE TONI, A.; TONCHIA, S. Performance measurement systems - Models, characteristics and measures. International Journal of Operations \& Production Management, v. 21, n. 1-2, p. 46-70, 2001. http://dx.doi. org/10.1108/01443570110358459

FOLAN, P.; BROWNE, J. A review of performance measurement: Towards performance management. Computers in Industry, v. 56, n. 7, p. 663-680, 2005. http://dx.doi.org/10.1016/j.compind.2005.03.001

GRIFFITHS, J. Balanced scorecard use in New Zealand government departments and crown entities. Australian Journal of Public Administration, v. 62, n. 4, p. 70-79, 2003. http://dx.doi.org/10.1111/j..2003.00350.x

GUNASEKARAN, A. et al. A framework for supply chain performance measurement. International Journal of Production Economics, v. 87, n. 3, p. 333-347, 2004. http://dx.doi.org/10.1016/j.ijpe.2003.08.003

HAN, K. H. et al. Two-stage process analysis using the process-based performance measurement framework and business process simulation. Expert Systems with Applications, v. 36, n. 3, p. 7080-7086, 2009. http://dx.doi. org/10.1016/j.eswa.2008.08.035

HODGKINSON, G. P. et al. Intuition in Organizations: Implications for Strategic Management. Long Range Planning, v. 42, n. 3, p. 277-297, 2009. http://dx.doi.org/10.1016/j.lrp.2009.05.003

HUANG, S. H.; KESKAR, H. Comprehensive and configurable metrics for supplier selection. International Journal of Production Economics, v. 105, n. 2, p. 510-523, 2007. http://dx.doi.org/10.1016/j.ijpe.2006.04.020

HUDSON, M. et al. Theory and practice in SME performance measurement systems. International Journal of Operations \& Production Management, v. 21, n. 8, p. 1096-1115, 2001. http://dx.doi.org/10.1108/ EUM0000000005587

INAMDAR, N.; KAPLAN, R. S. Applying the balanced scorecard in healthcare provider organizations. Journal of Healthcare Management, v. 47, n. 3, p. 179-195, 2002.

JOHNSTON, R.; PONGATICHAT, P. Managing the tension between performance measurement and strategy: coping strategies. International Journal of Operations \& Production Management, v. 28, n. 9-10, p. 941-967, 2008. http://dx.doi.org/10.1108/01443570810903104

KANJI, G. K.; SA, P. M. E. Kanji’s Business Scorecard. Total Quality Management, v. 12, n. 7-8, p. 898-905, 2001. http://dx.doi.org/10.1080/09544120100000013

KENNERLEY, M.; NEELY, A. Measuring performance in a changing business environment. International Journal of Operations \& Production Management, v. 23, n. 2, p. 213-229, 2003. http://dx.doi.

org/10.1108/01443570310458465

Fonte: Autores. 
Quadro 1. Continuação...

KRAKOVICS, F. et al. Defining and calibrating performance indicators of a 4PL in the chemical industry in Brazil. International Journal of Production Economics, v. 115, n. 2, p. 502-514, 2008. http://dx.doi.org/10.1016/j. ijpe.2008.05.016

KRAKOVICS, F. et al. Defining and calibrating performance indicators of a 4PL in the chemical industry in Brazil. International Journal of Production Economics, v. 115, n. 2, p. 502-514, 2008. http://dx.doi.org/10.1016/j. ijpe.2008.05.016

KUWAITI, M. E.; KAY, J. M. The role of performance measurement in business process re-engineering. International Journal of Operations \& Production Management, v. 20, n. 11-12, p. 1411-1426, 2000. http://dx.doi.org/10.1108/01443570010353086

LEE, A. H. I. et al. A fuzzy AHP and BSC approach for evaluating performance of IT department in the manufacturing industry in Taiwan. Expert Systems with Applications, v. 34, n. 1, p. 96-107, 2008. http://dx.doi. org/10.1016/j.eswa.2006.08.022

LIN, C. H.; HSIEH, p. J. A fuzzy decision support system for strategic portfolio management. Decision Support Systems, v. 38, n. 3, p. 383-398, 2004. http://dx.doi.org/10.1016/S0167-9236(03)00118-0

LIPE, M. G.; SALTERIO, S. E. The balanced scorecard: Judgmental effects of common and unique performance measures. Accounting Review, v. 75, n. 3, p. 283-298, 2000. http://dx.doi.org/10.2308/accr.2000.75.3.283

LOCH, C. H.; TAPPER, U. A. S. Implementing a strategy-driven performance measurement system for an applied research group. Journal of Product Innovation Management, v. 19, n. 3, p. 185-198, 2002. http://dx.doi. org/10.1111/1540-5885.1930185

MARCHAND, M.; RAYMOND, L. Researching performance measurement systems - An information systems perspective. International Journal of Operations \& Production Management, v. 28, n. 7-8, p. 663-686, 2008. http://dx.doi.org/10.1108/01443570810881802

MCADAM, R.; BAILIE, B. Business performance measures and alignment impact on strategy - The role of business improvement models. International Journal of Operations \& Production Management, v. 22, n. 9-10, p. 972-996, 2002. http://dx.doi.org/10.1108/01443570210440492

MELNYK, S. A. et al. Metrics and performance measurement in operations management: dealing with the metrics maze. Journal of Operations Management, v. 22, n. 3, p. 209-217, 2004. http://dx.doi.org/10.1016/j. jom.2004.01.004

MIR, R.; WATSON, A. Strategic management and the philosophy of science: The case for a constructivist methodology. Strategic Management Journal, v. 21, n. 9, p. 941-953, 2000. http://dx.doi.org/10.1002/10970266(200009)21:9\%3C941::AID-SMJ141\%3E3.0.CO;2-D

PAPALEXANDRIS, A. et al. Implementing the balanced scorecard in greece: A software firm's experience. Long Range Planning, v. 37, n. 4, p. 351-366, 2004. http://dx.doi.org/10.1016/j.lrp.2004.05.002

PAPKE-SHIELDS, K. E. et al. Strategic manufacturing planning systems and their linkage to planning system success. Decision Sciences, v. 33, n. 1, p. 1-30, 2002. http://dx.doi.org/10.1111/j.1540-5915.2002.tb01634.x

QUEZADA, L. E. et al. Method for identifying strategic objectives in strategy maps. International Journal of Production Economics, v. 122, n. 1, p. 492-500, 2009. http://dx.doi.org/10.1016/j.ijpe.2009.06.019

RODRIGUEZ, R. R. et al. Quantitative relationships between key performance indicators for supporting decision-making processes. Computers in Industry, v. 60, n. 2, p. 104-113, 2009. http://dx.doi.org/10.1016/j. compind.2008.09.002

SARKIS, J. Quantitative models for performance measurement systems - alternate considerations. International Journal of Production Economics, v. 86, n. 1, p. 81-90, 2003. http://dx.doi.org/10.1016/S0925-5273(03)00055-0

SHENHAR, A. J. et al. Project success: A multidimensional strategic concept. Long Range Planning, v. 34, n. 6, p. 699-725, 2001. http://dx.doi.org/10.1016/S0024-6301(01)00097-8

SINGH, S. K. et al. EIS support for the strategic management process. Decision Support Systems, v. 33, n. 1, p. 71-85, 2002. http://dx.doi.org/10.1016/S0167-9236(01)00129-4

YANG, C. L. et al. Manufacturing evaluation system based on AHP/ANP approach for wafer fabricating industry. Expert Systems with Applications, v. 36, n. 8, p. 11369-11377, 2009. http://dx.doi.org/10.1016/j.eswa.2009.03.023

YUAN, F. C.; CHIU, C. A hierarchical design of case-based reasoning in the balanced scorecard application. Expert Systems with Applications, v. 36, n. 1, p. 333-342, 2009. http://dx.doi.org/10.1016/j.eswa.2007.10.032

YUKSEL, I.; DAGDEVIREN, M. Using the fuzzy analytic network process (ANP) for Balanced Scorecard (BSC): A case study for a manufacturing firm. Expert Systems with Applications, v. 37, n. 2, p. 1270-1278, 2009.

http://dx.doi.org/10.1016/j.eswa.2009.06.002

Fonte: Autores. 


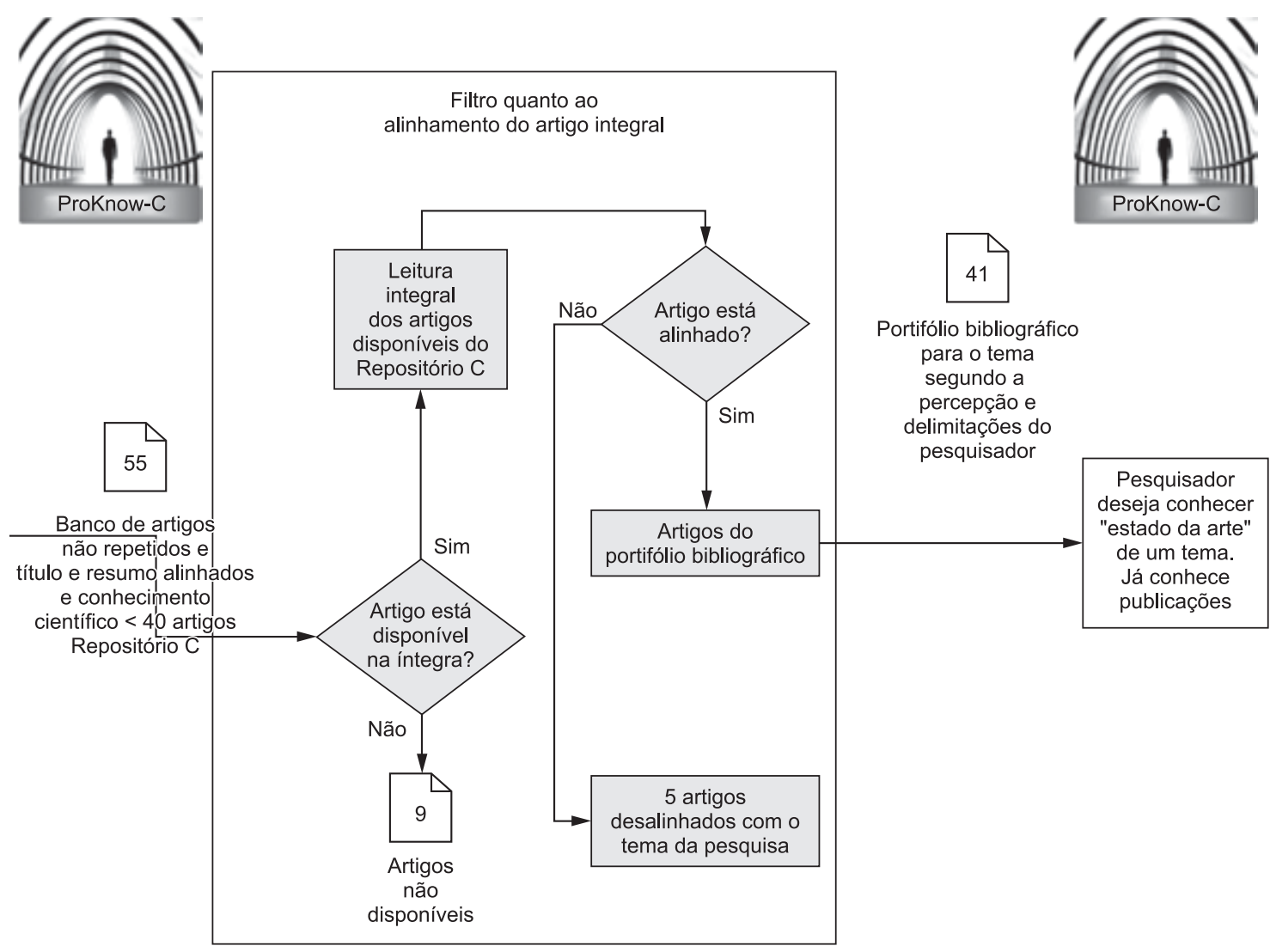

Figura 6. Fragmento final do processo para seleção de artigos. Fonte: Adaptado de Ensslin et al. (2010a).

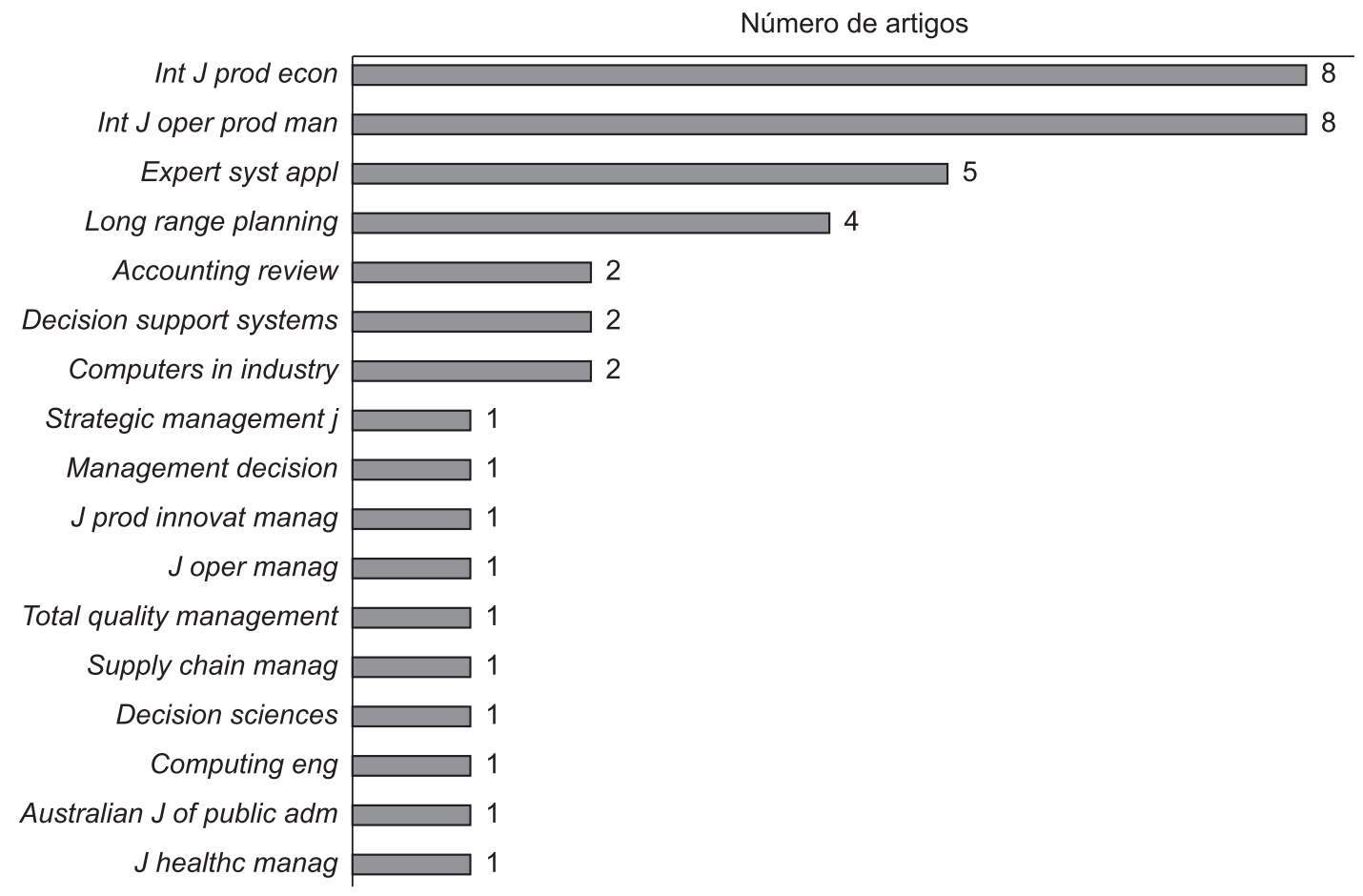

Figura 7. Número de artigos por periódicos. Fonte: Autores. 


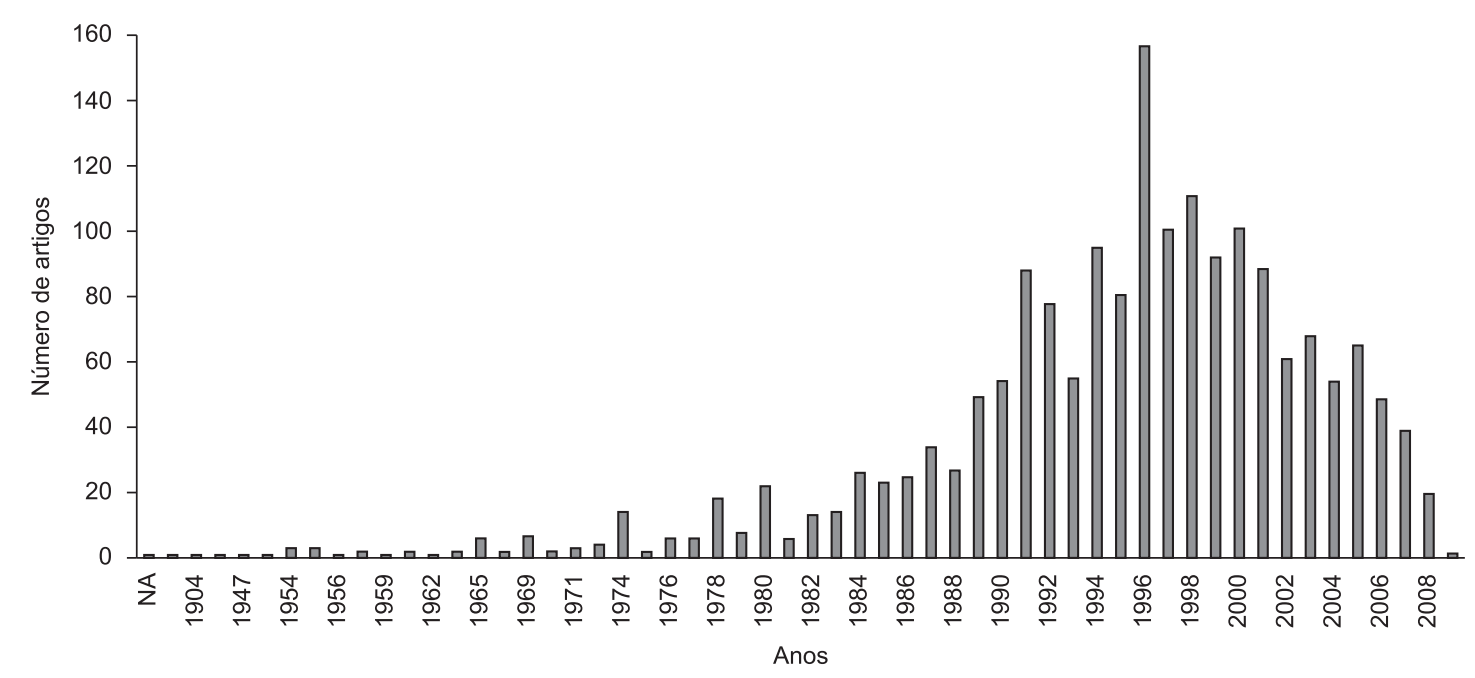

Figura 8. Número de referências utilizadas pelos artigos do portfólio, por temporalidade. Fonte: Autores.

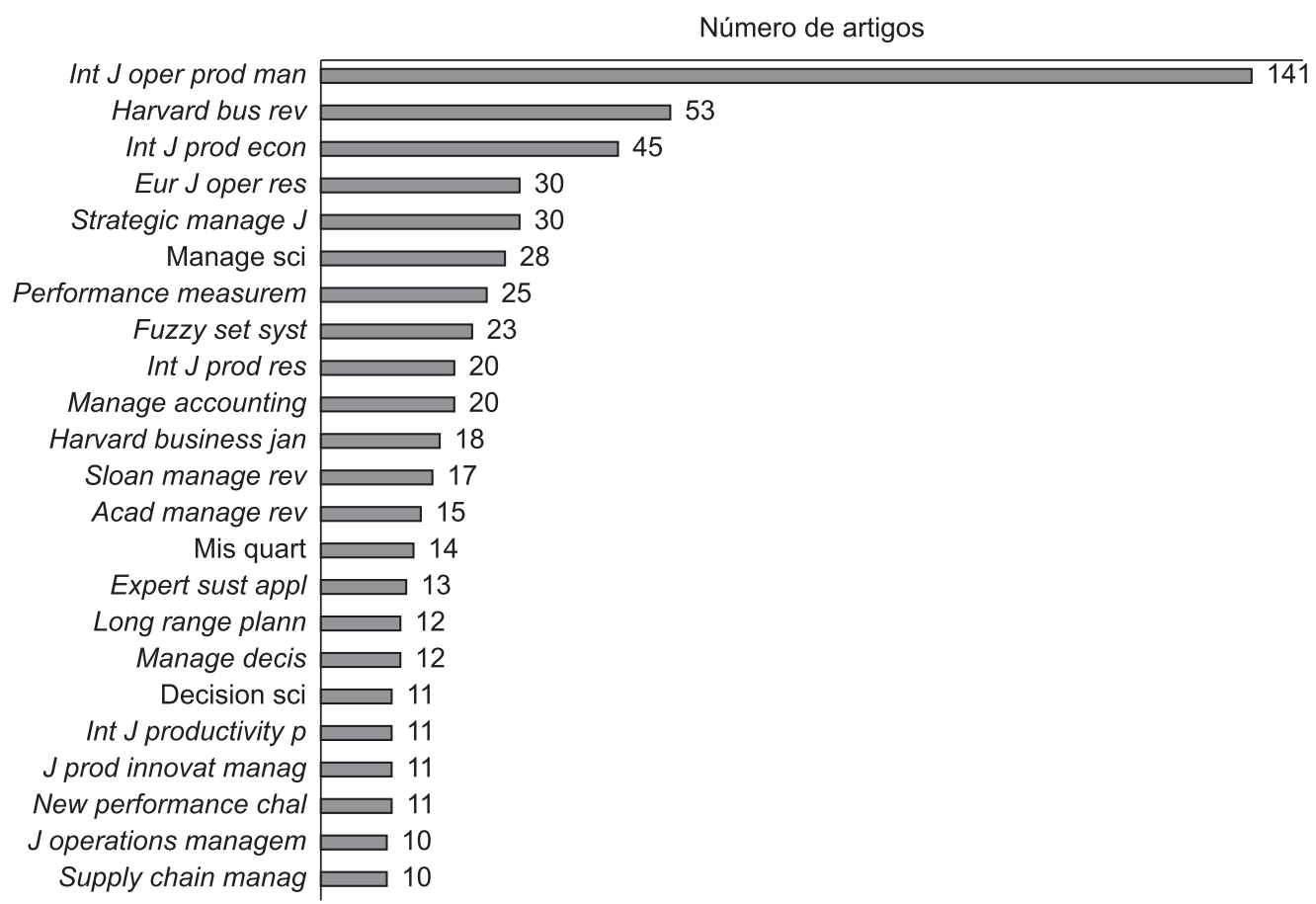

Figura 9. Número de referências utilizadas pelos artigos do portfólio, por periódico. Fonte: Autores.

teórico sobre avaliação de desempenho na perspectiva estratégica foi dividido em 3 etapas:

- Análise bibliométrica dos artigos selecionados;

- Análise bibliométrica das referências dos artigos selecionados;

- Classificação dos artigos conforme relevância acadêmica na amostra.

\subsubsection{Análise bibliométrica dos artigos selecionados}

Da análise bibliométrica dos artigos selecionados, resultaram 3 aspectos avaliados: i. Reconhecimento científico pelo número de citações, conforme detalhado na Tabela 2;

ii. Número de artigos por periódico, conforme apresentado na Figura 7;

iii. Número de artigos por autor. Para esse quesito, os pesquisadores Andy Neely e Mike Bourne foram os autores que tiveram dois dos seus artigos selecionados para o portfólio final (BOURNE et al., 2000; HUDSON; SMART; BOURNE, 2001; KENNERLEY; NEELY, 2003). Os demais autores tiveram apenas um de seus artigos selecionado. 
Tabela 2. Número de citações dos artigos do portfólio.

\begin{tabular}{|c|c|c|c|}
\hline Periódico & Título & Ano & $\begin{array}{l}\text { Nro de } \\
\text { Citações }\end{array}$ \\
\hline Accounting Review & $\begin{array}{c}\text { The balanced scorecard: Judgmental effects of common and unique } \\
\text { performance measures }\end{array}$ & 2000 & 317 \\
\hline $\begin{array}{l}\text { Int J Oper } \\
\text { Prod Man }\end{array}$ & $\begin{array}{c}\text { Designing, implementing and updating performance measurement } \\
\text { systems }\end{array}$ & 2000 & 274 \\
\hline Int J Prod Econ & A framework for supply chain performance measurement & 2004 & 257 \\
\hline Long Range Planning & Applying the Balanced Scorecard concept: An experience report & 2001 & 129 \\
\hline $\begin{array}{c}\text { Strategic Management } \\
\mathrm{J}\end{array}$ & $\begin{array}{l}\text { Strategic management and the philosophy of science: The case for a } \\
\text { constructivist methodology }\end{array}$ & 2000 & 126 \\
\hline Int J Oper Prod Man & Theory and practice in SME performance measurement systems & 2001 & 126 \\
\hline Long Range Planning & Project success: A multidimensional strategic concept & 2001 & 124 \\
\hline $\begin{array}{l}\text { Accounting } \\
\text { Review }\end{array}$ & $\begin{array}{c}\text { The balanced scorecard: Judgmental effects of performance measures } \\
\text { linked to strategy }\end{array}$ & 2004 & 124 \\
\hline Int J Oper Prod Man & Measuring performance in a changing business environment & 2003 & 120 \\
\hline $\begin{array}{l}\text { Int J Oper } \\
\text { Prod Man }\end{array}$ & $\begin{array}{c}\text { Performance measurement systems - Models, characteristics and } \\
\text { measures }\end{array}$ & 2001 & 110 \\
\hline J Healthc Manag & Applying the balanced scorecard in healthcare provider organizations & 2002 & 92 \\
\hline $\begin{array}{l}\text { Supply Chain } \\
\text { Management }\end{array}$ & $\begin{array}{l}\text { An innovative performance measurement method for supply chain } \\
\text { management }\end{array}$ & 2003 & 75 \\
\hline $\begin{array}{l}\text { J Oper } \\
\text { Manag }\end{array}$ & $\begin{array}{l}\text { Metrics and performance measurement in operations management: } \\
\text { dealing with the metrics maze }\end{array}$ & 2004 & 69 \\
\hline Computers In Industry & $\begin{array}{l}\text { A review of performance measurement: Towards performance } \\
\text { management }\end{array}$ & 2005 & 65 \\
\hline $\begin{array}{c}\text { Int } J \\
\text { Prod Econ }\end{array}$ & $\begin{array}{l}\text { Strategy management through quantitative modelling of performance } \\
\text { measurement systems }\end{array}$ & 2001 & 63 \\
\hline $\begin{array}{l}\text { J Prod } \\
\text { Innovat Manag }\end{array}$ & $\begin{array}{l}\text { Implementing a strategy-driven performance measurement system for } \\
\text { an applied research group }\end{array}$ & 2002 & 59 \\
\hline $\begin{array}{l}\text { Total Quality } \\
\text { Management }\end{array}$ & Kanji’s Business Scorecard & 2001 & 55 \\
\hline $\begin{array}{l}\text { Int J Oper } \\
\text { Prod Man }\end{array}$ & $\begin{array}{c}\text { Business performance measures and alignment impact on strategy - } \\
\text { The role of business improvement models }\end{array}$ & 2002 & 54 \\
\hline $\begin{array}{c}\text { Int } J \\
\text { Prod Econ }\end{array}$ & $\begin{array}{l}\text { Quantitative models for performance measurement systems - alternate } \\
\text { considerations }\end{array}$ & 2003 & 37 \\
\hline $\begin{array}{l}\text { Decision Support } \\
\text { Systems }\end{array}$ & A fuzzy decision support system for strategic portfolio management & 2004 & 35 \\
\hline $\begin{array}{l}\text { Expert } \\
\text { Syst Appl }\end{array}$ & $\begin{array}{c}\text { A fuzzy AHP and BSC approach for evaluating performance of IT } \\
\text { department in the manufacturing industry in Taiwan }\end{array}$ & 2008 & 34 \\
\hline $\begin{array}{l}\text { Decision Support } \\
\text { Systems }\end{array}$ & EIS support for the strategic management process & 2002 & 34 \\
\hline $\begin{array}{l}\text { Decision } \\
\text { Sciences }\end{array}$ & $\begin{array}{l}\text { Strategic manufacturing planning systems and their linkage to } \\
\text { planning system success }\end{array}$ & 2002 & 28 \\
\hline $\begin{array}{l}\text { Comput } \\
\text { Ind Eng }\end{array}$ & $\begin{array}{l}\text { Performance measurement of supply chain management: A balanced } \\
\text { scorecard approach }\end{array}$ & 2007 & 28 \\
\hline Long Range Planning & $\begin{array}{c}\text { Implementing the balanced scorecard in greece: A software firm's } \\
\text { experience }\end{array}$ & 2004 & 26 \\
\hline Int J Prod Econ & Comprehensive and configurable metrics for supplier selection & 2007 & 26 \\
\hline $\begin{array}{l}\text { Int J Oper } \\
\text { Prod Man }\end{array}$ & $\begin{array}{l}\text { The role of performance measurement in business process re- } \\
\text { engineering }\end{array}$ & 2000 & 26 \\
\hline $\begin{array}{l}\text { Australian J Of Public } \\
\qquad \text { Adm }\end{array}$ & $\begin{array}{c}\text { Balanced scorecard use in New Zealand government departments and } \\
\text { crown entities }\end{array}$ & 2003 & 26 \\
\hline
\end{tabular}

Fonte: Autores. 
Tabela 2. Continuação...

\begin{tabular}{|c|c|c|c|}
\hline Periódico & Título & Ano & $\begin{array}{l}\text { Nro de } \\
\text { Citações }\end{array}$ \\
\hline $\begin{array}{l}\text { Expert } \\
\text { Syst Appl }\end{array}$ & $\begin{array}{l}\text { A hierarchical design of case-based reasoning in the balanced } \\
\text { scorecard application }\end{array}$ & 2009 & 8 \\
\hline $\begin{array}{l}\text { Int J Oper } \\
\text { Prod Man }\end{array}$ & $\begin{array}{l}\text { Researching performance measurement systems - An information } \\
\text { systems perspective }\end{array}$ & 2008 & 7 \\
\hline $\begin{array}{l}\text { Int J Oper } \\
\text { Prod Man }\end{array}$ & $\begin{array}{c}\text { Managing the tension between performance measurement and } \\
\text { strategy: coping strategies }\end{array}$ & 2008 & 4 \\
\hline Management Decision & Using systems thinking to enhance strategy maps & 2008 & 3 \\
\hline $\begin{array}{l}\text { Computers } \\
\text { In Industry }\end{array}$ & $\begin{array}{l}\text { Quantitative relationships between key performance indicators for } \\
\text { supporting decision-making processes }\end{array}$ & 2009 & 3 \\
\hline $\begin{array}{c}\text { Int } J \\
\text { Prod Econ }\end{array}$ & $\begin{array}{c}\text { An objective-oriented and product-line-based manufacturing } \\
\text { performance measurement }\end{array}$ & 2008 & 2 \\
\hline Long Range Planning & Intuition in Organizations: Implications for Strategic Management & 2009 & 1 \\
\hline $\begin{array}{l}\text { Expert } \\
\text { Syst Appl }\end{array}$ & $\begin{array}{l}\text { Two-stage process analysis using the process-based performance } \\
\text { measurement framework and business process simulation }\end{array}$ & 2009 & 1 \\
\hline $\begin{array}{l}\text { Expert } \\
\text { Syst Appl }\end{array}$ & $\begin{array}{l}\text { Manufacturing evaluation system based on AHP/ANP approach for } \\
\text { wafer fabricating industry }\end{array}$ & 2009 & 1 \\
\hline $\begin{array}{c}\text { Int } J \\
\text { Prod Econ }\end{array}$ & $\begin{array}{c}\text { Taking operations strategy into practice: Developing a process for } \\
\text { defining priorities and performance measures }\end{array}$ & 2009 & 0 \\
\hline $\begin{array}{c}\text { Int } J \\
\text { Prod Econ }\end{array}$ & $\begin{array}{c}\text { Defining and calibrating performance indicators of a } 4 P L \text { in the } \\
\text { chemical industry in Brazil }\end{array}$ & 2008 & 0 \\
\hline Int J Prod Econ & Method for identifying strategic objectives in strategy maps & 2009 & 0 \\
\hline Expert Syst Appl & $\begin{array}{l}\text { Using the fuzzy analytic network process (ANP) for Balanced } \\
\text { Scorecard (BSC): A case study for a manufacturing firm }\end{array}$ & 2009 & 0 \\
\hline
\end{tabular}

Fonte: Autores.

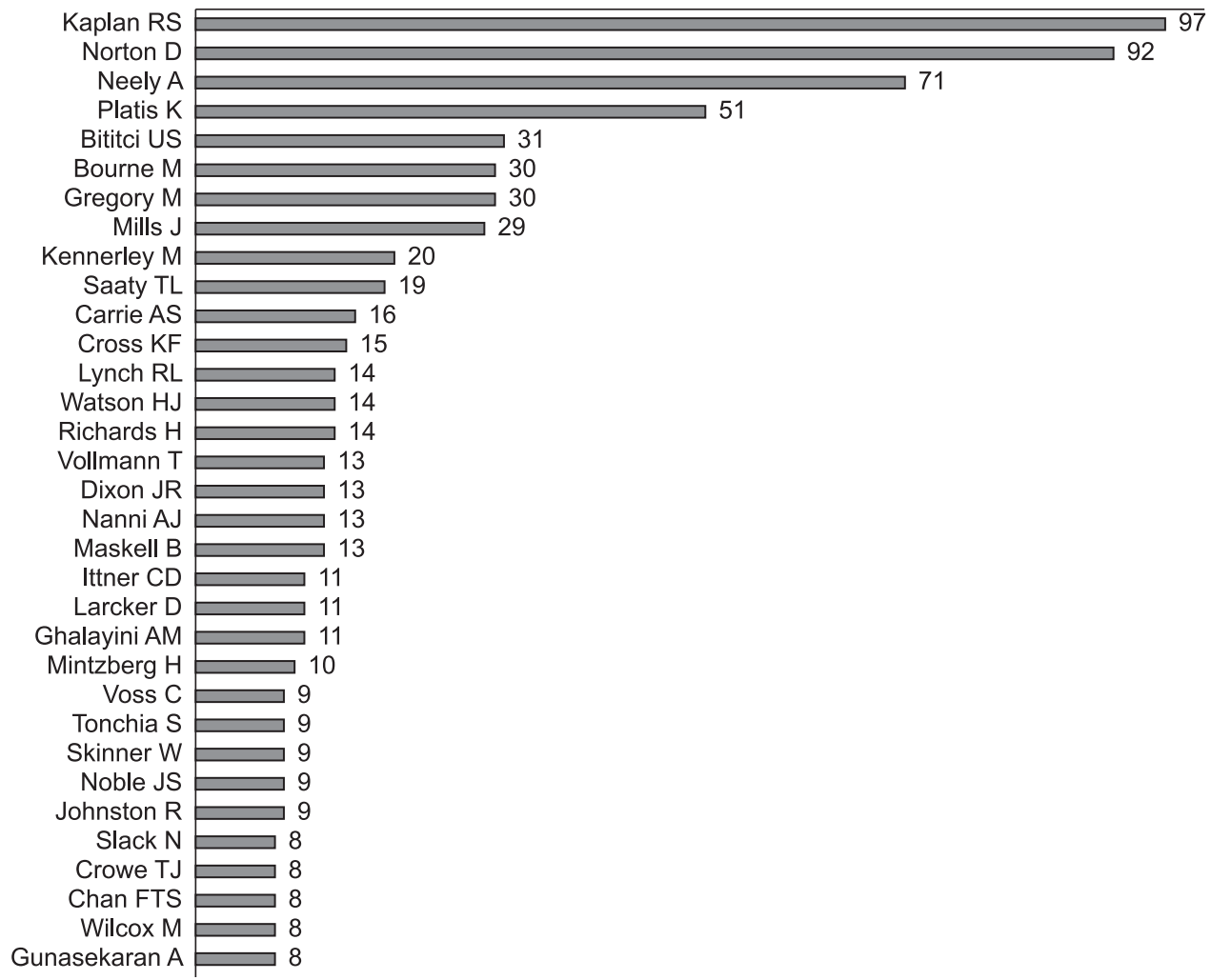

Figura 10. Número de citações nas referências por autor. Fonte: Autores. 


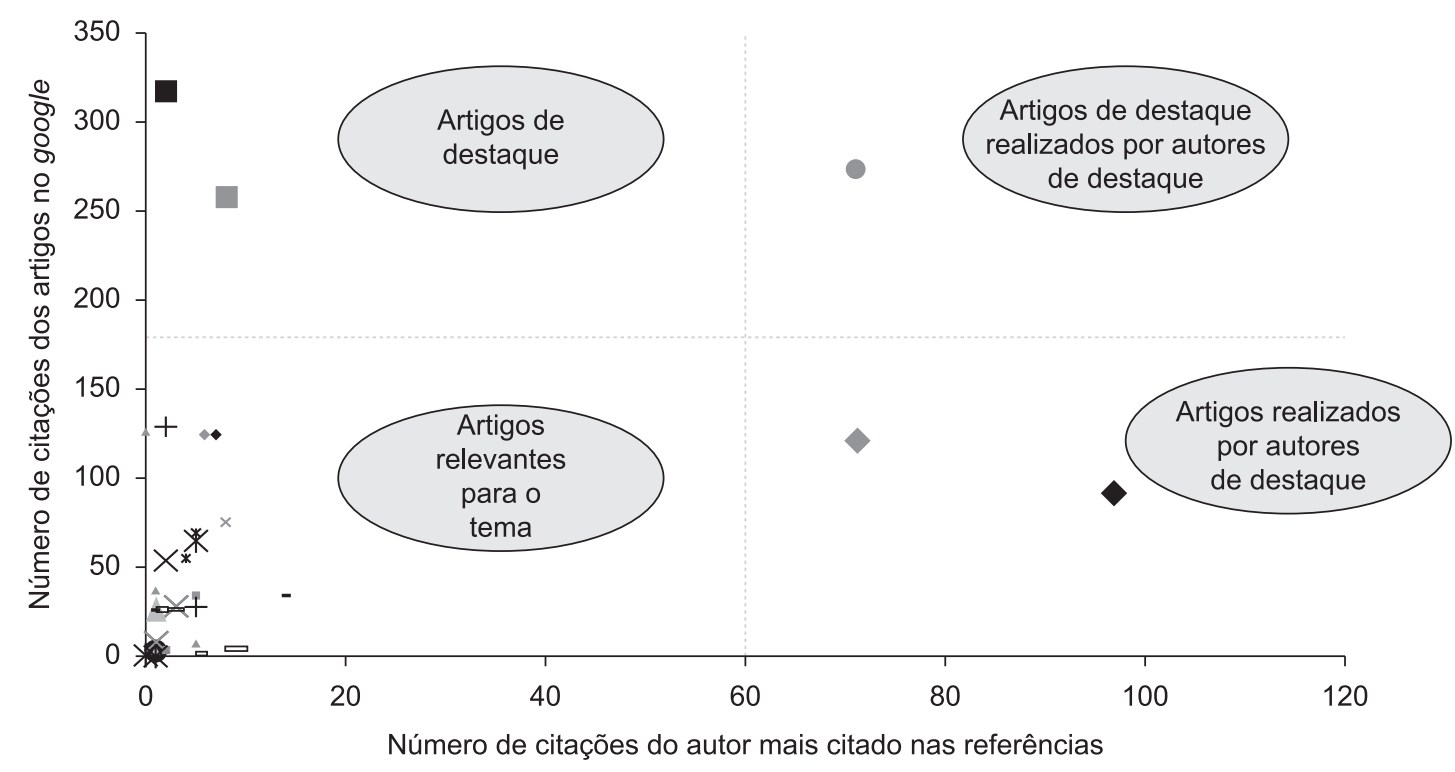

BOURNE, M. et al. Designing, implementing and updating performance measurement systems.

- International Journal of Operations \& Production Management, v. 20, n. 7, p. 754-771, 2000. http://dx.doi.org/10.1108/01443570010330739

LIPE, M. G.; SALTERIO, S. E. The balanced scorecard: Judgmental effects of common and unique

performance measures. Accounting Review, v. 75, n. 3, p. 283-298, 2000. http://dx.doi.org/10.2308/accr.2000.75.3.283

GUNASEKARAN, A et al. A framework for supply chain performance measurement. International

Journal of Production Economics, v. 87, n. 3, p. 333-347, 2004 http://dx.doi.org/10.1016/j.ijpe.2003.08.003

INAMDAR, N.; KAPLAN, R. S. Applying the balanced score card in health care provider organization. Journal of Healthcare Management, v. 47, n. 3, p. 179-195, 2002. PMid:12055900.

KENNERLEY, M.; NEELY, A. Measuring performance in a changing business environment.

International Journal of Operations \& Production Management, v. 23, n. 2, p. 213-229, 2003. http://dx.doi.org/10.1108/01443570310458465

Figura 11. Classificação dos artigos conforme sua relevância acadêmica. Fonte: Autores.

\subsubsection{Análise bibliométrica das referências dos artigos selecionados}

Com vistas a identificar os autores, artigos e periódicos que se destacam no contexto da pesquisa em pauta, foram catalogadas 3.450 referências citadas pelos 41 artigos que compõem o portfólio final.

Essas 3.450 referências foram analisadas sob as seguintes óticas:

i. Distribuição por ano de publicação, conforme ilustrado na Figura 8;

ii. Número de periódicos que publicaram os trabalhos, conforme Figura 9;

iii. Número de artigos por autor, conforme apresenta a Figura 10.

Quanto à análise de autores, o processo de análise de referências bibliográficas do portfólio final evidenciou as contribuições de Robert Kaplan e David Norton, especificamente pelas suas publicações sobre o método Balanced Scorecard-BSC.
Dos dois autores, apenas Robert Kaplan teve um artigo selecionado no portfólio final, dado que: i) os seus artigos referenciados datam de anos anteriores aos filtros da pesquisa, e ii) o periódico no qual publicavam suas contribuições não tem seus texto integrais disponíveis no portal da CAPES em março/2010.

\subsubsection{Classificação dos artigos conforme relevância acadêmica na amostra}

Para classificar os artigos do portfólio pela sua relevância acadêmica, o presente estudo adotou dois eixos de avaliação:

- Número de citações no Google Scholar (2010) que o artigo obteve desde sua publicação;

- Número de citações do autor mais citado na análise das referências bibliográficas dos artigos do portfólio, conforme discutido na seção anterior. 


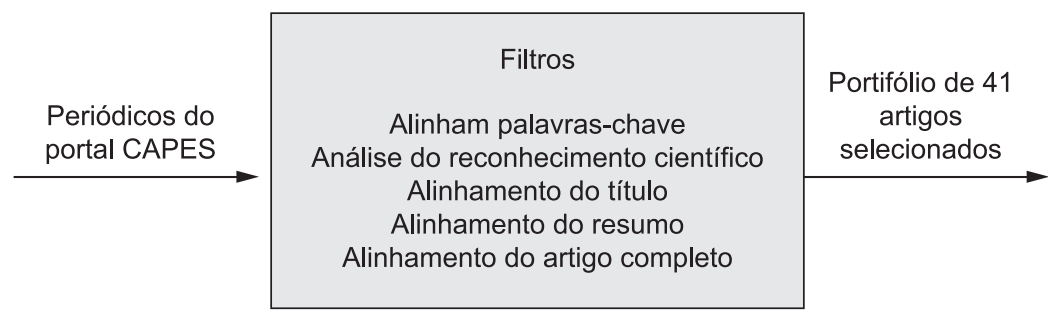

Figura 12. Resumo do processo para seleção de referências bibliográficas. Fonte: Autores.

Fruto dessa análise, a Figura 11 apresenta o gráfico com as duas dimensões definidas para classificar os artigos conforme sua relevância acadêmica e os artigos que se destacaram nessa análise.

Os quadrantes foram definidos ao deixar apenas os três artigos que mais se destacaram em cada dimensão, ou seja, aproximadamente 5\% do número de artigos do portfólio final.

\section{Conclusão}

Diante da importância no desenvolvimento de pesquisas acadêmicas em torno da avaliação de desempenho em uma perspectiva estratégica, o objetivo deste trabalho se centrou em apresentar um processo para selecionar referências bibliográficas para compor um referencial teórico sobre o contexto estudado.

Ao longo da seção "Procedimentos para Seleção de Referencial Teórico", o presente artigo apresentou os procedimentos para a seleção dos artigos mais relevantes sobre o tema e realizou uma análise para averiguar os principais trabalhos, autores e periódicos que publicaram sobre o tema avaliação de desempenho em um contexto estratégico.

Tal processo, conforme ilustrado na Figura 12, possibilitou realizar uma seleção sistemática de referências possíveis, que se iniciou com 2.345 trabalhos e culminou em um portfólio composto de 41 artigos explicitados na Quadro 1.

Além do processo de seleção de artigos para compor um referencial teórico sobre AD em uma perspectiva estratégica, o presente trabalho também realizou uma análise bibliométrica que evidenciou que, para o processo apresentado, os periódicos abaixo são os que mais se destacam quanto a publicações sobre o tema:

i. International Journal of Production Economics;

ii. International Journal of Operations \& Production Management.

Quanto aos autores, o processo evidenciou as contribuições dos pesquisadores Andy Neely e Mike Bourne, pois são os únicos que tiveram dois de seus trabalhos selecionados.

Além da análise dos 41 artigos que fazem parte do portfólio selecionado pelo processo apresentado, uma análise de suas referências bibliográficas foi realizada, e constatou que, além dos dois periódicos supracitados, se destaca o periódico Harvard Business Review.

Quanto à análise de autores, o processo de análise de referências bibliográficas do portfólio final evidenciou as contribuições de Robert Kaplan e David Norton, especificamente pelas suas publicações sobre o método Balanced Scorecard - BSC.

Como última análise, o presente artigo evidencia o trabalho de Bourne et al. (2000) que se sobressaiu na classificação de relevância acadêmica realizada sob a ótica de número de citações e como autor mais citado nas referências bibliográficas do artigos selecionados no portfólio final.

Os autores da pesquisa reiteram que este estudo não tenta construir um referencial teórico em si, mas contribui para que estudos sobre o contexto em pauta sejam baseados em um processo estruturado para a seleção e evidenciação dos artigos, autores e periódicos mais relevantes na área e que suportarão o arcabouço teórico dos trabalhos acadêmicos e científicos futuros. Dentre os possíveis projetos de pesquisa futuros, salienta-se a análise sistêmica do portfólio selecionado, com vistas a identificar oportunidades de pesquisa por meio da análise de conteúdo dos trabalhos do portfólio bibliográfico.

Uma limitação a ser explicitada na pesquisa, e evidenciada em alguns pontos deste texto, está na delimitação do campo amostral pelos artigos indexados pela base de dados Web of Science - ISI e disponibilizados no seu formato integral pelo sistema CAPES de periódicos em março de 2010.

Sobre essa limitação da base de dados, é importante citar que artigos que abordam teorias disruptivas, podem ter dificuldades em serem aceitos em periódicos tradicionais, como os indexados pela base de dados ISI e, consequentemente, terão menor probabilidade em serem selecionados em pesquisas dessa natureza (SUTTON; STAW, 1995).

Dentre as razões para a dificuldade de publicação de teorias disruptivas em periódicos tradicionais, se dá o fato de que os revisores desses periódicos nem sempre concordam ou se atualizam a ponto de aceitar a publicação de determinados artigos com teorias que causam rupturas drásticas ao status quo científico vigente. 


\section{Agradecimentos}

Os autores agradecem as considerações dos dois referees que gentilmente contribuíram para o aperfeiçoamento deste artigo.

\section{Referências}

ARAÚJO, C. A. A. Bibliometria: evolução histórica e questões atuais. Em Questão, v. 12, n. 1, p. 11-32, 2006.

BANA e COSTA, C.; ENSSLIN, L. Decision support systems in action: integrated application in a multicriteria decision aid process. European Journal of Operational Research, v. 113, p. 315-335, 1999. http://dx.doi. org/10.1016/S0377-2217(98)00219-7

BARNEY, J. Firm resources and sustained competitive advantage. Journal of Management, v. 17, p. 99-120, 1991. http://dx.doi.org/10.1177/014920639101700108

BARNEY, J.; WRIGHT, M.; KETCHEN, D. J. The resource-based view of the firm: ten years after 1991. Journal of Management, v. 27, p. 625-641, 2001. http:// dx.doi.org/10.1177/014920630102700601

BHAGWAT, R.; SHARMA, M. K. Performance measurement of supply chain management: A balanced scorecard approach. Computers \& Industrial Engineering, v. 53 , p. $43-62,2007$. http://dx.doi.org/10.1016/j. cie.2007.04.001

BITITCI, U. S.; SUWIGNJO, P.; CARRIE, A. S. Strategy management through quantitative modelling of performance measurement systems. International Journal of Production Economics, v. 69, p. 15-22, 2001. http://dx.doi.org/10.1016/S0925-5273(99)00113-9

BOURNE, M. et al. Designing, implementing and updating performance measurement systems. International Journal of Operations \& Production Management, v. 20, p. 754-771, 2000. http://dx.doi. org/10.1108/01443570010330739

CHEN, C. C. An objective-oriented and product-line-based manufacturing performance measurement. International Journal of Production Economics, v. 112, p. 380-390, 2008. http://dx.doi.org/10.1016/j.ijpe.2007.03.016

DE LIMA, E. P.; DA COSTA, S. E. G.; DE FARIA, A. R. Taking operations strategy into practice: developing a process for defining priorities and performance measures. International Journal of Production Economics, v. 122, p. 403-418, 2009. http://dx.doi.org/10.1016/j. ijpe.2009.06.022

DE MORAES, L. et al. The multicriteria analysis for construction of benchmarkers to support the Clinical Engineering in the Healthcare Technology Management. European Journal of Operational Research, v. 200, p. 607-615, 2010. http://dx.doi. org/10.1016/j.ejor.2009.01.018

EISENHARDT, K. M.; MARTIN, J. A. Dynamic capabilities: what are they? Strategic Management Journal, v. 21, p. 1105-1121, 2000. http://dx.doi. org/10.1002/1097-0266(200010/11)21:10/11\%3C110 5::AID-SMJ133\%3E3.0.CO;2-E

ENSSLIN, L. Disciplina de MCDA-C do Programa de Pós Graduação em Engenharia da Produção. UFSC, 2010. Notas de aula.
ENSSLIN, L.; DUTRA, A.; ENSSLIN, S. R. MCDA: a constructivist approach to the management of human resources at a governmental agency. International Transactions in Operational Research, v. 7, p. 79-100, 2000 . http://dx.doi.org/10.1111/j.1475-3995.2000. tb00186.x

ENSSLIN, L. et al. ProKnow-C, knowledge development process - constructivist. Processo técnico com patente de registro pendente junto ao INPI. 2010a.

ENSSLIN, L. et al. Avaliação do desempenho de empresas terceirizadas com o uso da metodologia multicritério de apoio à decisão-construtivista. Revista Pesquisa Operacional, v. 30, 125-152, $2010 \mathrm{~b}$.

GOOGLE. Google Scholar, 2010.

GUNASEKARAN, A.; PATEL, C.; MCGAUGHEY, R. E. A framework for supply chain performance measurement. International Journal of Production Economics, v. 87, p. 333-347, 2004. http://dx.doi.org/10.1016/j. ijpe.2003.08.003

HAN, K. H.; KANG, J. G.; SONG, M. Two-stage process analysis using the process-based performance measurement framework and business process simulation. Expert Systems with Applications, v. 36, p. 7080-7086, 2009. http://dx.doi.org/10.1016/j.eswa.2008.08.035

HELFAT, C. E.; PETERAF, M. A. The dynamic resource-based view: capability lifecycles. Strategic Management Journal, v. 24, p. 997-1010, 2003. http:// dx.doi.org/10.1002/smj.332

HUANG, S. H.; KESKAR, H. Comprehensive and configurable metrics for supplier selection. International Journal of Production Economics, v. 105, p. 510-523, 2007. http://dx.doi.org/10.1016/j.ijpe.2006.04.020

HUDSON, M.; SMART, A.; BOURNE, M. Theory and practice in SME performance measurement systems. International Journal of Operations \& Production Management, v. 21, p. 1096-1115, 2001. http://dx.doi. org/10.1108/EUM0000000005587

INAMDAR, N.; KAPLAN, R. S. Applying the balanced scorecard in healthcare provider organizations. Journal of Healthcare Management, v. 47, p. 179-195, 2002. PMid:12055900

JOHNSTON, R.; PONGATICHAT, P. Managing the tension between performance measurement and strategy: coping strategies. International Journal of Operations \& Production Management, v. 28, p. 941-967, 2008. http://dx.doi.org/10.1108/01443570810903104

JURAN, J. M. A qualidade desde o projeto. São Paulo: Pioneira, 1997.

KARLSSON, C. Researching operations management. London: Routledge, 2008.

KENNERLEY, M.; NEELY, A. Measuring performance in a changing business environment. International Journal of Operations \& Production Management, v. 23, n. 213-229, 2003.

KETCHEN, D.; BOYD, B.; BERGH, D. Research methodology in strategic management. Organizational Research Methods, v. 11, p. 643-658, 2008. http:// dx.doi.org/10.1177/1094428108319843

KRAKOVICS, F. et al. Defining and calibrating performance indicators of a 4PL in the chemical industry in Brazil. International Journal of Production Economics, 
v. 115, p. 502-514, 2008. http://dx.doi.org/10.1016/j. ijpe.2008.05.016

KUNC, M. Using systems thinking to enhance strategy maps. Management Decision, v. 46, p. 761-778, 2008. http://dx.doi.org/10.1108/00251740810873752

KUWAITI, M. E.; KAY, J. M. The role of performance measurement in business process re-engineering. International Journal of Operations \& Production Management, v. 20, p. 1411-1426, 2000. http://dx.doi. org/10.1108/01443570010353086

LACERDA, R. T. O.; ENSSLIN, L.; ENSSLIN, S. R. A Performance measurement framework in portfolio management: a constructivist case. Management Decision, v. 49, p. 1-15. 2011a. http://dx.doi. org/10.1108/00251741111126530

LACERDA, R. T. O.; ENSSLIN, L.; ENSSLIN, S. R. A performance measurement view of it project management. The International Journal of Productivity and Performance Management, v. 60, p. 132-151, 2011 b. http://dx.doi.org/10.1108/17410401111101476

LEE, A. H. I.; CHEN, W. C.; CHANG, C. J. A fuzzy AHP and BSC approach for evaluating performance of IT department in the manufacturing industry in Taiwan. Expert Systems with Applications, v. 34, p. 96-107, 2008. http://dx.doi.org/10.1016/j.eswa.2006.08.022

LIN, C. H.; HSIEH, P. J. A fuzzy decision support system for strategic portfolio management. Decision Support Systems, 38, 383-398, 2004. http://dx.doi.org/10.1016/ S0167-9236(03)00118-0

LIPE, M. G.; SALTERIO, S. E. The balanced scorecard: judgmental effects of common and unique performance measures. Accounting Review, v. 75, p. 283-298, 2000. http://dx.doi.org/10.2308/accr.2000.75.3.283

LOCH, C. H.; TAPPER, U. A. S. Implementing a strategydriven performance measurement system for an applied research group. Journal of Product Innovation Management, v. 19, p. 185-198, 2002. http://dx.doi. org/10.1111/1540-5885.1930185

MAKADOK, R. Toward a synthesis of the resource-based and dynamic-capability views of rent creation. Strategic Management Journal, v. 22, p. 387-401, 2001. http:// dx.doi.org/10.1002/smj.158

MARCHAND, M.; RAYMOND, L. Researching performance measurement systems - An information systems perspective. International Journal of Operations \& Production Management,v. 28, p. 663-686, 2008. http://dx.doi.org/10.1108/01443570810881802

MCADAM, R.; BAILIE, B. Business performance measures and alignment impact on strategy - the role of business improvement models. International Journal of Operations \& Production Management, v. 22, p. 972-996, 2002. http://dx.doi. org/10.1108/01443570210440492

MELNYK, S. A.; STEWART, D. M.; SWINK, M. Metrics and performance measurement in operations management: dealing with the metrics maze. Journal of Operations Management, v. 22, p. 209-217, 2004. http://dx.doi. org/10.1016/j.jom.2004.01.004

MINTZBERG, H. et al. The strategy process: concepts, contexts, cases. Upper Saddle River: Prentice-Hall, 2003.
MORGAN, G.; SMIRCICH, L. The case for qualitative research. Academy of Management. The Academy of Management Review (pre-1986), v. 5, p. 491, 1980.

MORGAN, N. A.; VORHIES, D. W.; MASON, C. H. Research notes and commentaries market orientation, marketing capabilities, and firm performance. Strategic Management Journal, v. 30, p. 909-920, 2009. http:// dx.doi.org/10.1002/smj.764

PAPALEXANDRIS, A.; IOANNOU, G.; PRASTACOS, G. P. Implementing the balanced scorecard in greece: a software firm's experience. Long Range Planning, v. 37, p. 351-366, 2004. http://dx.doi.org/10.1016/j. lrp.2004.05.002

PAPKE-SHIELDS, K. E.; MALHOTRA, M. K.; GROVER, V. Strategic manufacturing planning systems and their linkage to planning system success. Decision Sciences, v. 33, p. 1-30, 2002. http://dx.doi. org/10.1111/j.1540-5915.2002.tb01634.x

PARETO, V. Cours d'economie politique. Lausanne: F. Rouge, 1986. v.1

PODSAKOFF, P. M. et al. The influence of management journals in the 1980s and 1990s. Strategic Management Journal, v. 26, p. 473-488, 2005. http://dx.doi. org/10.1002/smj.454

PORTER, M. Competitive strategy: techniques for analyzing industries and competitors. New York: Free Press, 1980.

QUEZADA, L. E. et al. Method for identifying strategic objectives in strategy maps. International Journal of Production Economics, v. 122, p. 492-500, 2009. http://dx.doi.org/10.1016/j.ijpe.2009.06.019

RODRIGUEZ, R. R.; SAIZ, J. J. A.; BAS, A. O. Quantitative relationships between key performance indicators for supporting decision-making processes. Computers in Industry, v. 60, p. 104-113, 2009. http://dx.doi. org/10.1016/j.compind.2008.09.002

SARKIS, J. Quantitative models for performance measurement systems - alternate considerations. International Journal of Production Economics, v. 86, p. 81-90, 2003. http://dx.doi.org/10.1016/ S0925-5273(03)00055-0

SHENHAR, A. J. et al. Project success: A multidimensional strategic concept. Long Range Planning, v. 34, p. 699-725, 2001. http://dx.doi.org/10.1016/ S0024-6301(01)00097-8

SIMONS, R.; DÁVILA, A.; KAPLAN, R. Performance measurement \& control systems for implementing strategy: text \& cases. Upper Saddle River, N.J.:Prentice Hall, 2000.

SUTTON, R. I.; STAW, B. M. What theory is not. Administrative Science Quarterly, v. 40, p. 371-384, 1995. http://dx.doi.org/10.2307/2393788

TASCA, J. et al. An approach for selecting a theoretical framework for the evaluation of training programs. Journal of European Industrial Training, v. 34, p. 631-655, 2010. http://dx.doi.org/10.1108/03090591011070761

TEECE, D. J. Explicating dynamic capabilities: the nature and microfoundations of (sustainable) enterprise performance. Strategic Management Journal, v. 28, p. 1319-1350, 2007. http://dx.doi.org/10.1002/smj.640 
THE THOMSON CORPORATION. EndNote X. 2. ed. The Thomson Corporation, 2008.

TRANFIELD, D.; DENYER, D.; SMART, P. Towards a methodology for developing evidence-informed management knowledge by means of systematic review. British Journal of Management, v. 14, p. 207-222, 2003. http://dx.doi.org/10.1111/1467-8551.00375

TRIVIÑOS, A. N. S. Introdução à pesquisa em ciências sociais: a pesquisa qualitativa em educação: o positivismo, a fenomenologia, o marxismo. São Paulo: Atlas, 1987.

WADE, M.; HULLAND, J. Review: the resource-based view and information systems research: review, extension, and suggestions for future research. Mis Quarterly, v. 28, p. 107-142, 2004.

WINTER, S. Understanding dynamic capabilities. Strategic Management Journal, v. 24, p. 991-995, 2003. http:// dx.doi.org/10.1002/smj.318

YANG, C. L.; CHUANG, S. P.; HUANG, R. H. Manufacturing evaluation system based on AHP/ANP approach for wafer fabricating industry. Expert Systems with Applications, v. 36, p. 11369-11377, 2009. http:// dx.doi.org/10.1016/j.eswa.2009.03.023

YUAN, F. C.; CHIU, C. A hierarchical design of case-based reasoning in the balanced scorecard application. Expert Systems with Applications, v. 36, p. 333-342, 2009. http://dx.doi.org/10.1016/j.eswa.2007.10.032

YUKSEL, I.; DAGDEVIREN, M. Using the fuzzy analytic network process (ANP) for Balanced Scorecard (BSC): a case study for a manufacturing firm. Expert Systems with Applications, v. 37, p. 1270-1278, 2009. http:// dx.doi.org/10.1016/j.eswa.2009.06.002

ZAHRA, S.; SAPIENZA, H.; DAVIDSSON, P. Entrepreneurship and dynamic capabilities: a review, model and research agenda. Journal of Management Studies, v. 43, p. 917-955, 2006. http://dx.doi. org/10.1111/j.1467-6486.2006.00616.x

ZOLLO, M.; WINTER, S. G. Deliberate learning and the evolution of dynamic capabilities. Organization Science, v. 13, p. 339-351, 2002. http://dx.doi.org/10.1287/ orsc. 13.3 .339 .2780 